\title{
Neuronal Activity at Synapse Resolution: Reporters and Effectors for Synaptic Neuroscience
}

\author{
Francesco Gobbo ${ }^{1,2 *}$ and Antonino Cattaneo ${ }^{1 *}$ \\ ${ }^{1}$ Bio@SNS Laboratory of Biology, Scuola Normale Superiore, Pisa, Italy, ${ }^{2}$ Centre for Discovery Brain Sciences, University of \\ Edinburgh, Edinburgh, United Kingdom
}

The development of methods for the activity-dependent tagging of neurons enabled a new way to tackle the problem of engram identification at the cellular level, giving rise to groundbreaking findings in the field of memory studies. However, the resolution of activity-dependent tagging remains limited to the whole-cell level. Notably, events taking place at the synapse level play a critical role in the establishment of new memories,

OPEN ACCESS

Edited by:

David Blum,

INSERM U1172 Centre de Recherche Jean Pierre Aubert,

France

Reviewed by:

Sabine Levi,

Institut National de la Santé et de la Recherche Médicale (INSERM),

France

Kurt Gottmann,

Heinrich Heine University of

Düsseldorf, Germany

*Correspondence:

Francesco Gobbo

fgobbo@ed.ac.uk

Antonino Cattaneo

antonino.cattaneo@sns.it

Received: 13 June 2020 Accepted: 31 August 2020 Published: 21 October 2020

Citation:

Gobbo F and Cattaneo A (2020) Neuronal Activity at Synapse Resolution: Reporters and Effectors

for Synaptic Neuroscience. Front. Mol. Neurosci. 13:572312. doi: 10.3389/fnmol.2020.572312 and strong experimental evidence shows that learning and synaptic plasticity are tightly linked. Here, we provide a comprehensive review of the currently available techniques that enable to identify and track the neuronal activity with synaptic spatial resolution. We also present recent technologies that allow to selectively interfere with specific subsets of synapses. Lastly, we discuss how these technologies can be applied to the study of learning and memory.

Keywords: synapse, imaging, synaptic engram, synaptic activity indicators, synaptic activity reporter

\section{INTRODUCTION}

Synapses are the physical locus where information is transmitted between neurons. Synapses have specific molecular properties that modulate their effectiveness in propagating neuronal transmission in response to past activity, which confers them a central place in the neurobiology of learning and memory. Of the approximately 30,000 synapses on a single CA1 neuron, the activation of a few hundreds is probably sufficient to activate the cell and initiate action potentials (Routtenberg, 2015). Hence, specific ensembles of synapses could represent unitary bits of information, such as a definite area of space or an element of a memory trace. Which synapses out of the many thousands are responsible for representing these memory elements? Electrophysiological recordings from whole neurons can identify pathways of activation, but lack the ability of creating a map of individual representations at the synaptic level.

Bi-directional modifications of synaptic strength, collectively referred to as synaptic plasticity, have long been regarded as the neural correlate of learning. For instance, the experience-dependent increase of synaptic responses (such as long-term potentiation) is generally believed to be responsible for the behavioral responses observed in associate learning (Martin and Morris, 2002). While not all changes associated to learning and memory involve changes in synaptic transmission (Poo et al., 2016), a comprehensive of the theory of memory would be incomplete without taking 
into account the role of synaptic changes (Langille and Brown, 2018; Sossin, 2018; Williams and Kyrke-Smith, 2018). Synaptic engrams, the ensemble of synapses undergoing plasticity during learning, represent a parallel trace to cellular engrams. Synaptic engrams mediate the formation of cell assemblies and the probability of their reactivation (Josselyn et al., 2015; Ryan et al., 2015; Lisman et al., 2018), and their role is likely to be more evident in non-associative forms of memories, such as episodic-like memories involving spatial and temporal information (Morris, 2006). How this set of synapses interacts with cellular engrams, and how engram cells are interconnected, is largely still unclear (Poo et al., 2016). For instance, it has been shown that individual memories maintain separated synaptic representations even when they largely overlap at the cellular level (Abdou et al., 2018). Ensembles of active or plastic synapses need not be the lifelong locus of memory storage to be considered candidate synaptic engrams, since engrams are not static entities, but they can evolve over time (Dudai, 2011; Poo et al., 2016). Hence, synaptic engrams can be crucial for memory formation and encoding by mediating the temporal evolution of the engram circuit, even if the original synaptic trace is gradually lost because of protein turnover and spine loss (Mongillo et al., 2017).

To demonstrate the causal relevance of any physiological processes in learning, two conditions have to be met: (i) they need to be identified and take place during learning and (ii) interfering with such process, either positively or negatively, should have a corresponding effect on the ability to form memories (Martin et al., 2000; Tonegawa et al., 2015a). Experiments inducing depression (long-term depression, LTD) or potentiation (long-term potentiation, LTP) of synapses response suggest that altering the synapse status also impacts memory recall (Nabavi et al., 2014), although experiments with synaptic resolutions are still lacking. When it comes to the specific sets of synapses activated by experience, testing the two criteria has long been an experimental challenge, due to the lack of suitable techniques to identify and manipulate active synapses in a reliable manner (Takeuchi et al., 2014). In recent years, however, a number of techniques have been described to map and intervene on ensembles of synapses, based on their activity. Here, we present the currently available technologies and critically discuss how these could be applied to the study of memory at the synaptic level (Table $\mathbf{1}$ ).

\section{TAGGING SYNAPTIC ENGRAMS: COMPARISON WITH CELLULAR ENGRAMS}

The identification of immediate early genes (IEGs), genes that are rapidly transcribed when neurons are electrically activated (Yap and Greenberg, 2018), opened the way to the definition of cellular engrams, i.e., populations of neurons that are believed to embody specific memory traces in the brain (Sakaguchi and Hayashi, 2012; Mayford, 2014). In these experiments, neurons activated during a certain behavioral paradigm are genetically tagged by driving the expression of the desired transgene from an exogenous transcription factor (TF) under an IEG promoter (usually, c-fos). This TF is sensitive to drugs that can be delivered to the animal and can restrict the expression of the transgene, depending on their availability (Reijmers et al., 2007; Ramirez et al., 2013). If opto- or chemogenetic proteins are expressed during the learning phase, the role of this neuronal population can be tested by re-activating them at wish or silencing them during natural recall. The results by the Mayford, Tonegawa, and Josselyn groups support the idea that the ensemble of neurons that participate in learning are also involved in the retrieval of a memory (Josselyn and Tonegawa, 2020). In these experiments, neurons are regarded as unitary entities: all neurons, whose activity exceeds a given threshold in the time window controlled by the drug administration, will be tagged, and the transgene will be expressed in the whole cell. Later reactivation causes tagged neurons to fire at the same level, thus losing information on the subcellular distribution of inputs or input specificity. It is remarkable that such reactivation paradigms are sufficient to elicit behavioral responses consistent with the encoded memory, even if so far the majority of behavioral paradigms used rely on contextual fear conditioning (Liu et al., 2012) and place preference (Ramirez et al., 2013), and sometimes only some stimulation protocols are effective (Ryan et al., 2015).

The engram cell theory, which regards engram cells as the unitary elements of memory allocation and storage, is not informative on the possibility that unitary elements of memory are represented at the subcellular level. Given the complexity of the neuronal inputs, it is possible that ensembles of individual synapses (Sakaguchi and Hayashi, 2012; Dudai and Morris, 2013; Nomoto and Inokuchi, 2018)—or of clustered groups of synapses (Kastellakis et al., 2015) - contribute to the initial representation of a memory, at least temporarily, to its storage in the form of a synaptic engram. Furthermore, little is known about how neurons are recruited into cellular engrams, nor which synaptic connections are relevant in their parallel or hierarchical activation. Studies of learning-related plasticity show that plasticity is synapse-specific, i.e., it can occur at some but not all synapses made by an individual neuron. Multiple engrams can also co-exist as separate traces even if these share a subset of neurons (Abdou et al., 2018). Thus, synaptic engrams may exist embedded within cellular engrams, and synaptic connections between individual engram cells in an engram cell assembly can be stabilized differently. Even if it is possible that the ultimate site of memory store resides in a stabilized neural circuit (Tonegawa et al., 2015b), there is strong evidence that active synapses during learning are necessary for the initial storage of a memory and for its later recall (Poo et al., 2016).

We can therefore ask whether synaptic engrams can be defined using similar operational criteria that have been used to define the cell engrams, i.e., synapses activated and modified by a learning experience, whose reactivation is necessary and sufficient to support memory retrieval. One major difficulty in the identification of synaptic engrams is the need to develop experimental techniques to map and act on these synaptic ensembles, based on the activity-dependent long-lasting 
TABLE 1 | List of the main currently available sensors and effectors for synaptic activity.

\begin{tabular}{|c|c|c|c|c|c|}
\hline Indicator & Brief description & Type & Applications & Expression & Source \\
\hline \multicolumn{6}{|l|}{ Genetic } \\
\hline Actin-GCaMP2 & $\begin{array}{l}\text { Calcium imaging reporter fused } \\
\text { to beta actin. Enriched at spines }\end{array}$ & Activity & In vivo live imaging & Constitutive & Addgene 18928 \\
\hline GCaMP3 & Calcium imaging reporter & Activity & $\begin{array}{l}\text { In vivo live imaging. } \\
\text { Applied to image } \\
\text { Drosophila presynaptic boutons } \\
\text { activity. Tuft dendritic potentials } \\
\text { in mice }\end{array}$ & Constitutive & $\begin{array}{l}\text { Tian et al. (2009) } \\
\text { Addgene 43917, } 32644\end{array}$ \\
\hline GCaMP6s & $\begin{array}{l}\text { Calcium imaging reporter with } \\
\text { sufficient SNR to detect synaptic } \\
\text { events }\end{array}$ & Activity & $\begin{array}{l}\text { In vivo live imaging. Cortical } \\
\text { areas, deeper regions with } \\
\text { chronic windows (hippocampus). } \\
\text { Pre- and postsynaptic structures. } \\
\text { Extensively tested in rodents, } \\
\text { zebrafish and Drosophila }\end{array}$ & $\begin{array}{l}\text { Constitutive and floxed forms. } \\
\text { Suitable for AAV delivery and } \\
\text { in utero electroporation. } \\
\text { Transgenic animals available }\end{array}$ & $\begin{array}{l}\text { Chen et al. (2013) } \\
\text { Addgene 40753, } 100842 \text { (AAV } \\
\text { vector), and others } \\
\text { Transgenic mouse lines } \\
\text { available: Camk2a-tTA (B6.Cg- } \\
\text { Tg(Camk2a-tTA)1Mmay/DboJ, } \\
\text { Jax \#007004, RRID:IMSR_JAX: } \\
\text { 007004, and others }\end{array}$ \\
\hline jGCaMP7b & $\begin{array}{l}\text { Calcium imaging reporter with } \\
\text { sufficient SNR to detect synaptic } \\
\text { events }\end{array}$ & Activity & $\begin{array}{l}\text { In vivo live imaging. Cortical } \\
\text { areas, deeper regions possible } \\
\text { with chronic windows } \\
\text { (hippocampus). Pre- and } \\
\text { postsynaptic structures (mostly } \\
\text { rodents) }\end{array}$ & $\begin{array}{l}\text { Constitutive and floxed forms. } \\
\text { Suitable for AAV delivery and, } \\
\text { likely, in utero electroporation }\end{array}$ & $\begin{array}{l}\text { Dana et al. (2019) } \\
\text { Addgene 104489, } 104497 \\
\text { Addgene } 135419 \text { (variant } \\
\text { enriched at axons) }\end{array}$ \\
\hline jRECO1a & $\begin{array}{l}\text { Red fluorescent calcium imaging } \\
\text { reporter with sufficient SNR to } \\
\text { detect synaptic events }\end{array}$ & Activity & $\begin{array}{l}\text { In vivo live imaging. Cortical } \\
\text { areas, such as visual cortex. } \\
\text { Tested in rodents, Drosophila, } \\
\text { and zebrafish }\end{array}$ & $\begin{array}{l}\text { Constitutive for AAV delivery. } \\
\text { Floxed versions available. Other } \\
\text { methods possible }\end{array}$ & $\begin{array}{l}\text { Addgene 100852, 100853, } \\
100854 \\
\text { Drosophila strain } \\
\text { PBac20 } \times \text { UAS-IVS-NES- } \\
\text { jRCaMP1a-p10VK00005 Flybase } \\
\text { ID FBti0180188 }\end{array}$ \\
\hline $\begin{array}{l}\text { XCaMP series: XCaMP-Y } \\
\text { XCaMP-R }\end{array}$ & $\begin{array}{l}\text { Multicolor variants of calcium } \\
\text { imaging reporters with sufficient } \\
\text { SNR to detect synaptic events }\end{array}$ & Activity & $\begin{array}{l}\text { In vivo live imaging. Cortical } \\
\text { areas, such as visual cortex. } \\
\text { Imaging in the hippocampus is } \\
\text { possible with longer wavelength } \\
\text { sensors }\end{array}$ & Constitutive & Inoue et al. (2019) \\
\hline Syntagma & $\begin{array}{l}\text { Photoconvertible CAMPARI } \\
\text { variant (green to red). The } \\
\text { photoconversion requires } \\
\text { calcium influx and UV light (via } \\
\text { either an optic cannula or } \\
\text { imaging objective) }\end{array}$ & Activity & $\begin{array}{l}\text { In vivo live imaging. } \\
\text { Fixed tissue. } \\
\text { Pre- (PSD95.FingR fusion) and } \\
\text { postsynaptic (synaptophysin } \\
\text { fusion) variants available. Tested } \\
\text { in rodents }\end{array}$ & Constitutive. AAV delivery & $\begin{array}{l}\text { Perez-Alvarez et al. (2020) } \\
\text { Addgene } 119738 \text { (pre) } \\
\text { Addgene } 119736 \text { (post) }\end{array}$ \\
\hline $\begin{array}{l}\text { SF-iGluSnFR A184S (higher } \\
\text { SNR) or S72A (higher } \\
\text { temporal fidelity) variants }\end{array}$ & $\begin{array}{l}\text { Fluorescent reporter for } \\
\text { glutamate release }\end{array}$ & Activity & $\begin{array}{l}\text { In vivo live imaging. Cortical } \\
\text { areas, tested in the rodent and } \\
\text { ferret visual and sensory cortex }\end{array}$ & Constitutive. AAV delivery & $\begin{array}{l}\text { Marvin et al. (2018) } \\
\text { Addgene } 106200 \text { (S72V variant), } \\
\text { Addgene } 106198 \text { (A184S } \\
\text { variant) }\end{array}$ \\
\hline SEP-GluA1 & $\begin{array}{l}\text { AMPA receptor trafficking and } \\
\text { exposure }\end{array}$ & Plasticity (E-LTP) & In vivo live imaging & $\begin{array}{l}\text { Constitutive. In utero } \\
\text { electroporation. Knock-in mouse } \\
\text { line reported }\end{array}$ & $\begin{array}{l}\text { Addgene 24000, Addgene } \\
64942 \\
\text { Transgenic line: Graves et al. } \\
\text { (2020) }\end{array}$ \\
\hline
\end{tabular}

Red fluorescent calcium imaging reporter with sufficient SNR to detect synaptic events

Multicolor variants of calcium imaging reporters with sufficient Photoconvertible CAMPAR variant (green to red). The photoconversion requires un influx and UV light (via ing objective)

AMPA receptor trafficking and exposure 
TABLE 1 | Continued

\begin{tabular}{|c|c|c|c|c|c|}
\hline Indicator & Brief description & Type & Applications & Expression & Source \\
\hline GFP-GluA1 & $\begin{array}{l}\text { AMPA receptor trafficking and } \\
\text { exposure }\end{array}$ & Plasticity (E-LTP) & In vivo imaging. Fixed tissue & Constitutive and inducible & Addgene 34857 \\
\hline AS-PaRac1 & $\begin{array}{l}\text { Local translation of light-sensitive } \\
\text { Rac1 }\end{array}$ & Plasticity (L-LTP) & In vivo live imaging. Fixed tissue & $\begin{array}{l}\text { Constitutive or activity } \\
\text { dependent. AAV delivery and } \\
\text { In utero electroporation reported }\end{array}$ & Hayashi-Takagi et al. (2015) \\
\hline SA-Ch & Local translation of ChR2 variant & Plasticity (L-LTP) & Live imaging. Fixed tissue & Inducible. In utero electroporation & Gobbo et al. (2017) \\
\hline Diffusible fillers & $\begin{array}{l}\text { Fluorescent fillers of the GFP and } \\
\text { RFP families can be used to } \\
\text { image changes in dimensions } \\
\text { and new spine formation or } \\
\text { elimination. Membrane-anchored } \\
\text { fluorescent proteins can also be } \\
\text { used to increase signal }\end{array}$ & $\begin{array}{l}\text { Structural plasticity (changes in } \\
\text { dimension and } \\
\text { formation/removal of spines) }\end{array}$ & $\begin{array}{l}\text { Live imaging. Validated in } \\
\text { multiple models including } \\
\text { rodents, Drosophila, zebrafish }\end{array}$ & $\begin{array}{l}\text { Any method of delivery. Multiple } \\
\text { transgenic lines are available }\end{array}$ & $\begin{array}{l}\text { Multiple commercial sources. } \\
\text { Transgenic lines: B6.Cg- } \\
\text { Tg(Thy1-YFP)HJrs/J Jax } \\
\text { \#003782 and many others }\end{array}$ \\
\hline $\begin{array}{l}\text { PSD-95 fluorescent variants } \\
\text { (or Homer1c fusions) }\end{array}$ & $\begin{array}{l}\text { Fluorescent postsynaptic } \\
\text { proteins (excitatory synapses) }\end{array}$ & $\begin{array}{l}\text { Structural plasticity (mainly } \\
\text { formation/loss) }\end{array}$ & Live imaging & $\begin{array}{l}\text { Multiple methods of delivery. } \\
\text { Transient or inducible expression } \\
\text { may be preferable }\end{array}$ & $\begin{array}{l}\text { Addgene } 125694,125693 \text {, } \\
\text { 133785, and others }\end{array}$ \\
\hline $\begin{array}{l}\text { Gephyrin fluorescent } \\
\text { variants }\end{array}$ & $\begin{array}{l}\text { Fluorescent postsynaptic } \\
\text { proteins (inhibitory synapses) }\end{array}$ & $\begin{array}{l}\text { Structural plasticity (mainly } \\
\text { formation/loss) }\end{array}$ & Live imaging & $\begin{array}{l}\text { Multiple methods of delivery. } \\
\text { Transient or inducible expression } \\
\text { may be preferable }\end{array}$ & $\begin{array}{l}\text { Addgene } 126217,73918 \text {, and } \\
\text { others }\end{array}$ \\
\hline e-GRASP & $\begin{array}{l}\text { Complementation system to } \\
\text { visualize synapses between } \\
\text { defined pre- and postsynaptic } \\
\text { neuron populations. It can be } \\
\text { activity dependent. It can be } \\
\text { applied to inhibitory connections } \\
\text { (test needed) }\end{array}$ & $\begin{array}{l}\text { Structural plasticity (changes in } \\
\text { dimensions and numbers), } \\
\text { plasticity of connections }\end{array}$ & $\begin{array}{l}\text { Live imaging possible. Fixed } \\
\text { tissue }\end{array}$ & $\begin{array}{l}\text { Constitutive via AAV delivery. } \\
\text { Activity-dependent expression is } \\
\text { dependent on the tetON system } \\
\text { (cfos-tTA) }\end{array}$ & $\begin{array}{l}\text { Addgene } 111579 \text { (cyan } \\
\text { pre-eGRASP) } 111582 \text { (tet- } \\
\text { dependent yellow pre-eGRASP), } \\
111580 \text { (yellow pre-eGRASP), } \\
111584 \text { (post-eGRASP) } \\
\text { Addgene } 120309 \text { (cfos-tTA) }\end{array}$ \\
\hline \multicolumn{6}{|l|}{ Chemical } \\
\hline FM dyes & Neurotransmitter exocytosis & Activity & Live imaging & Injected & Commercial sources available \\
\hline $\begin{array}{l}\text { Oregon Green } \\
488 \text { BAPTA-1, Fluo-4 (and } \\
\text { others) }\end{array}$ & Pre- or postsynaptic activity & Activity & In vivo live imaging & $\begin{array}{l}\text { Injected, delivered with patch } \\
\text { pipettes or cell electroporation }\end{array}$ & Commercial source available \\
\hline
\end{tabular}

We indicate their main use and commercial course, if available. Some plasmids and all chemicals listed can be purchased from a number of specialized for-profit commercial companies. Where the tool is particularly diffuse, we indicate some example sources that reflect the original or most diffuse forms (or transgenic lines). Abbreviations: AAV, adeno-associated vector; GFP, green fluorescent protein; RFP, red fluorescent protein; SNR, signal-to-noise ratio. 
modifications they undergo during a learning process. At the neuron level, IEGs expression proved to be a reasonable and robust hallmark to identify candidate cellular engrams. Indeed, IEGs have a series of sound properties for an engram candidate, such as being expressed at the time of memory formation (Guzowski et al., 1999) and being intrinsically related to synaptic and cellular plasticity (Gallo et al., 2018; Yap and Greenberg, 2018). Moving from the whole cell to the single-synapse level feels much like moving into a terra incognita, where many of the molecular events taking place in the active synapse are known, but a comprehensive picture of their relative importance is still missing. Nevertheless, for a set of synapses to form a memory-relevant trace, they should be active during the learning phase-even though silent synapses (Wang et al., 2019) and newly formed synapses may also play a role (Xu et al., 2009; Yang et al., 2009). As we shall see in the next sessions, a number of molecular events that follow synaptic activation have been used to develop reporters to identify active synapses in learning tasks (Figure 1).

\section{IMAGING SYNAPTIC ACTIVITY}

One obvious possibility to identify active synapses is to image their activity with single-synapse resolution. The introduction of reporters of neural activity with sufficient sensitivity to measure synaptic events made it possible to extend the analysis to single-synapse resolution. A now widely diffuse class of reporters of synaptic activity is represented by geneticallyencoded calcium indicators (GECIs): now almost two-decades old, circularly permutated green fluorescent protein (cpEGFP)based GCaMP series is based on the insertion of a calmodulin and a calmodulin-binding peptide (M13) within the EGFP protein

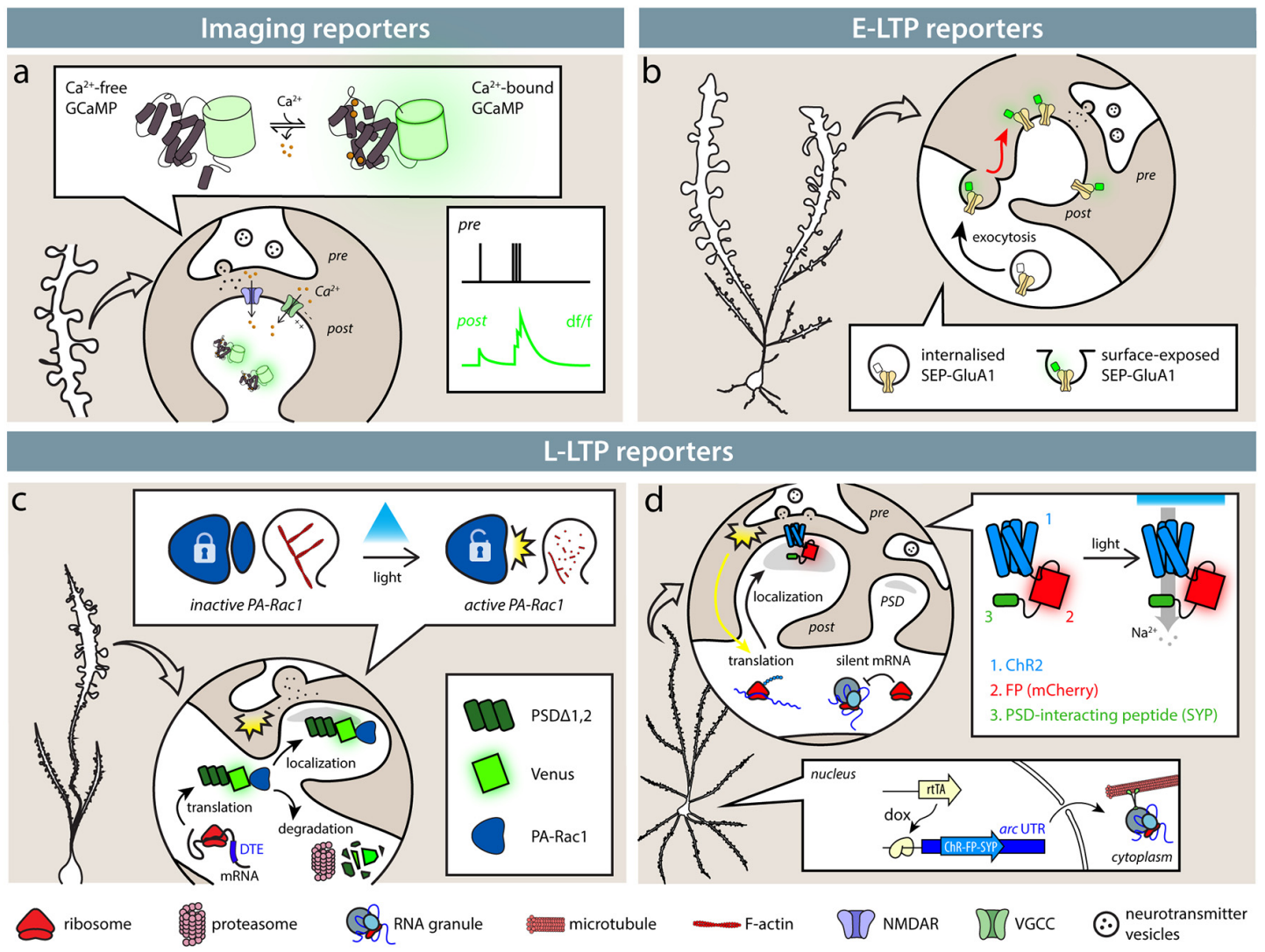

FIGURE 1 | Available tools identify synapses based on their activity. (A) Imaging reporters (genetically encoded calcium indicators, GECls), such as calcium (Ca ${ }^{2+}$ ) indicators, allow the experimenter to identify active synapses in live imaging. $\mathrm{Ca}^{2+}$ influx through NMDARs (blue) and VGCCs (green), as well as from intracellular stores, causes GECls, such as GCaMP6s, to shift from a dark to a fluorescent state. Synaptic activity then results in an instantaneous change in fluorescence. (B) Exposure of SEP-tagged AMPA receptors (SEP-GluA1) labels synapses during E-LTP. In intracellular stores, SEP fluorescence is quenched by the acidic pH, so that only exposed AMPA receptors following synaptic activity are fluorescent. (C,D) SA-Ch and AS-PaRac1 reporters are expressed at synapses following potentiation induction. (C) AS-PaRac1 is expressed at synapses following potentiation thanks to Arc dendritic targeting element (DTE) in the $3^{\prime}$-UTR. PSD $\Delta 1,2$ anchors the protein to the postsynaptic density (PSD) and promotes its degradation outside the synapse. AS-PaRac1 encodes a light-sensitive Rac1 form fused to Venus fluorescent protein. When it activated by blue light, it causes actin depolymerization and spine shrinkage. (D) SA-Ch encodes the ChR2 variant ChETA fused to the red fluorescent protein (RFP) mCherry and to SYP tag interacting with the PSD. Arc UTR sequences maintain the mRNA in repressed state and allow its translation at potentiated synapses. Like ChR2, SA-Ch is a cation channel that causes depolarizing photocurrents, but in principle, it could be substituted by opsins of other ionic specificities. 
sequence (Nakai et al., 2001; Figure 1A). Calcium binding forces calmodulin to assume a more compact shape, causing a net increase of EGFP fluorescence. Calcium is a potent signaling ion for synaptic activity: the influx of calcium ions at the presynaptic site is responsible for neurotransmitter release (Südhof, 2012), whereas at the postsynaptic site, $\mathrm{Ca}^{2+}$ ions can flow in through NMDA receptor (NMDAR) and $\mathrm{Ca}^{2+}$-selective channels (Higley and Sabatini, 2012).

The first successful recording of synaptic activity with synaptic resolution was performed fusing GCaMP2 sensor to synaptophysin, making it possible to visualize the incoming action potential at presynaptic terminals (Dreosti et al., 2009). A proof-of-principle observation of synaptic transmission at the postsynaptic site was performed by fusing GCaMP2 to actin, hence enriching the sensor to actin-rich spines (Mao et al., 2008). However, it was not until the development of GECIs with higher sensitivity and intensity that reliable imaging of synaptic activation could be achieved. By expressing GCaMP3 in the somatosensory cortex, Xu et al. (2012) visualized the response of tuft dendrites to whisker sensing. A major improvement was the introduction of GCaMP6s: expressing GCaMP6s in the visual cortex, Chen et al. (2013) were able to detect single synaptic events, showing that single synapses were selectively activated by visual stimuli of different orientations. Orientation preference was stable over at least 27 days of repeated imaging of the same neurons (Chen et al., 2013). The latest class of GECIs has thus proven able to identify synaptic events with submicron resolution, hence in principle allowing the recording of the activity of single synapses across days. To date, the two GECI variants that allow this level of resolution are GCaMP6s (Chen et al., 2013) and jGCaMP7b (Dana et al., 2019). They now exist in multicolor, which could find a useful application when it comes to spectra overlap or cell-type specific analysis (Inoue et al., 2019). For instance, the red indicator jRECO1b has been used in conjunction with GCaMP6s in the visual cortex to visualize the synaptic activity of the synapses on layer 5 neurons and of axons from the lateromedial area simultaneously (Dana et al., 2016). Synthetic calcium indicators have also proven to be reliable tools to image synaptic activity, with performance equal (if not sometimes superior) to GECIs, and have been applied extensively to the imaging of synaptic activity in cortical areas, such as the somatosensory cortex, where spontaneous and evoked responses were detected with two-photon imaging (Varga et al., 2011).

\section{Significance of Synaptic Activity Imaging}

Identifying active synapses during the presentation of a given sensory stimulation is a fundamental first step toward the identification of a synaptic correlate of memory representation and encoding. Stability is generally believed to be a necessary feature for a candidate synaptic representation of a memory; indeed, the constancy of orientation selectivity in the visual cortex seems to meet this requirement. Similar considerations were applied to neurons in other cortical areas using synthetic calcium indicators, such as Oregon-Green Baptal or Fluo 5F. In the auditory cortex, single spines in pyramidal neurons can be repeatedly activated by a sound of their preferred tone frequency (Chen et al., 2011), whereas in the barrel cortex, synaptic selectivity has been measured by visualizing synaptic activity in response to single whisker stimulation (Takahashi et al., 2012).

It is not clear, however, what the ensemble of active synapses represents, whether they simply reflect the transmission of information between the imaged neurons, or they actually encode a memory for the specific stimulus. In principle, potentiation of synaptic transmission can be inferred with GECIs from an increase in amplitude of the calcium transients. In hippocampal slices, increases in $\Delta \mathrm{F} / \mathrm{F}$ ratios (the standard measure to express changes in fluorescence with indicators) after optical LTP induction correlate with changes in spine volume and potentiation of synaptic transmission measured in patch-clamp mode (Wiegert et al., 2018). If applied in vivo, this could provide an estimate of functional potentiation of synaptic transmission at synapse resolution. By expressing GCaMP at Kenyon cells presynaptic sites onto mushroom bodies in Drosophila, Bilz et al. (2020) showed that different odors can be represented at the level of separate synaptic boutons and display input-specific synaptic plasticity during associative learning. Furthermore, the time course of potentiation could be measured too, distinguishing between transient and long-lasting effects; however, it is not clear if all types of plasticity could be measured in this way, and it would be essential to estimate carefully the amplitude and variance of the $\Delta F / F$ synaptic events in the calculation of the baseline.

\section{Technical Considerations}

In principle, imaging synaptic activity could provide a large amount of information. This information could be so large that it poses the difficulty of how to interpret and analyze this type of data, extracting consistent patterns out of the multitude of synaptic events. In practice, however, the field of view is limited by spatial and temporal resolution constraints. State-of-the-art imaging with opto-acoustic deflectors (AODs) can reasonably image volumes of around $10^{5} \mu^{3}$, which correspond to a cube of $50 \mu \mathrm{m}$ per side (Schultz et al., 2016; Verstraelen et al., 2018). Larger volumes can be images using random-access methods, which are based on a prior definition of the sites of interest to be imaged within volumes of around $150 \mu \mathrm{m}$ per side (FernándezAlfonso et al., 2014). Similar results are obtained with advanced imaging setups coupling AODs with Bessel laser beams, making it possible to record at $30 \mathrm{~Hz}$ from around $5 \times 10^{6} \mu \mathrm{m}^{3}$ (equivalent to $270 \times 270 \times 60 \mu \mathrm{m}$ ) with submicron resolution (Lu et al., 2017).

Imaging live synaptic activity poses additional experimental limitations. First, it only allows imaging of brain areas that are accessible to two-photon microscopes. In practice, this often translates into cortical areas, where imaging can be performed through optical windows or thinned skull (Chen et al., 2011). This has also precluded imaging during most behavioral paradigms, because two-photon imaging is generally performed on head-fixed animals. In particular, this precludes its application to spatial tasks that are not based on virtual reality (Gauthier and Tank, 2018). Notably, the first record of synaptic $\mathrm{Ca}^{2+}$ transients with a head-mounted two-photon microscope 
has only been reported in 2017 (Zong et al., 2017), after previous attempts suffered technical limitations that prevented effective in vivo recording of submicrometric structures, such as spines. Imaging deeper brain areas, such as the hippocampus, at synaptic resolution can be achieved coupling two-photon imaging with GRIN lenses located within the brain to gain access to the desired brain region (Attardo et al., 2015; Meng et al., 2019). It is therefore conceivable to couple the head-mounted two-photon microscopes with GRIN lenses to image synaptic activity in the hippocampus during learning tasks. Technological advances in optical imaging promise to push the limits of temporal ( $\mathrm{Wu}$ et al., 2020) and spatial resolutions (Lu et al., 2017) to allow live imaging of synaptic activity.

\section{Other Synaptic Activity Imaging Techniques}

cpEGFP-based GECIs are the most common class of calcium sensors employed in neuroscience research. Other classes of GECIs exist, for example, those based on FRET emission between two fluorescent proteins with different emission spectra (Kotlikoff, 2007). Efficient voltage sensors have also been described recently, and while they have been applied to the visualization of the activity of presynaptic terminals in Drosophila (Yang et al., 2016), imaging voltage changes at the synaptic resolution probably needs variants with even higher brightness and signal-to-noise ratios (SNRs; Bando et al., 2019). In addition, fluorescent indicators for glutamate release and $\mathrm{pH}$-sensitive dyes for vesicle fusion have been described. In particular, the glutamate sensor iGluSnFR (Marvin et al., 2013) and its variants, which signal glutamate binding by an increase in fluorescence, have shown generally good performance in detecting synaptic events of glutamate release (Jensen et al., 2019), making them a viable alternative to image synaptic activity. Recently, an improved iGluSnFR variant has been employed in vivo to visualize orientation selectivity response at individual synapses in the mouse and ferret visual cortex (Marvin et al., 2018). Genetic $\mathrm{pH}$-sensitive fluorescent indicators expressed on the membrane of neurotransmitter vesicles can be used to monitor presynaptic activity when they fuse with the plasma membrane, although to our knowledge, they have so far only been employed in large synapses (neuromuscular junctions, calix of Held; Kavalali and Jorgensen, 2014). Lastly, also sensors to image intracellular signaling events have been developed (e.g., CaMKII and RhoA activation), although their use in vivo has been limited. A comprehensive description of these sensors is beyond the scope of this article, and we refer to other excellent reviews (Padamesey and Emptage, 2011; Lee et al., 2016; Lin and Schnitzer, 2016).

Recently, a method to take a "snapshot" of active synapses at a given time has been described (Perez-Alvarez et al., 2020). This technique, named Syntagma, is based on the green fluorescent protein (GFP) CAMPARI that can be photoconverted into a red form with blue-light illumination in the presence of high $\mathrm{Ca}^{2+}$ concentrations (Moeyaert et al., 2018). By fusing the CAMPARI fluorescent protein to either presynaptic synaptophysin or a postsynaptic anti-PSD95 intracellular antibody, they were able to provide a snapshot of active synapses during illumination.
Computational offline analysis enables the identification of thousands of individual active synapses and the description of their status (active-inactive) from their fluorescence (red-green). This approach frees calcium imaging from the constraints of live recording, thus extending it to non-restrained behavior and enlarging the imaging volume, with the only constraint being the area reached by sufficient light power. Furthermore, any brain area can in principle be analyzed with this technology by using an appropriate optic guide.

While the focus of this review lies in genetic methods, so that the reporters can be expressed as transgenes in the brain using standard molecular genetics techniques, such as adenoassociated vectors (AAVs) or Cre-lox systems (Sjulson et al., 2016; Haery et al., 2019), in some cases, chemical compounds can be used to image synaptic activity in vivo or in acute slices. These can usually be delivered in soluble form via patch pipettes or similar [e.g., Fluo-4, Fluo-5F, Oregon Green BAPTA-1 (OGB)] or injected in a form that can be taken up by neurons (e.g., OGB-AM). Organic calcium dyes are bright calcium indicators and have been successfully used to monitor synaptic activity in vivo (Varga et al., 2011; Winnubst et al., 2015). In the same way, fillers, such as organic fluorophores, can be used to image structural plasticity at synapses (see next section; FernándezAlfonso et al., 2014). Presynaptic activity can be monitored with organic dyes that accumulate in neurotransmitter vesicles or their membrane (e.g., FM dyes); usually, neural activity results in negative changes in fluorescence due to vesicle fusing with the plasma membrane, thus limiting their use to ex vivo preparations (Kavalali and Jorgensen, 2014). In some cases, specific vesicle types (e.g., dopaminergic vesicles) can be labeled with fluorescent neurotransmitter analogues to monitor synaptic activity (Pereira et al., 2016).

\section{SYNAPTIC EVENTS DURING POTENTIATION}

From the perspective of synaptic engrams, we must distinguish between synaptic activity and synaptic plasticity mechanisms. Activity at synapses during the learning phase may contribute differently to neuronal representations: while some of the active synapses may be involved in long-term information storage, others may just reflect signal transmission, neuronal computation, or activity noise (Pouget et al., 2013). An appealing candidate for synaptic storage of memories is the ensemble of synapses undergoing potentiation (Mayford et al., 2012; Rogerson et al., 2014; Takeuchi et al., 2014). During a learning process, patterns of neural activity representing the learned events cause changes in the strength of synaptic connections (Whitlock et al., 2006). According to Semon's engram definition (Schacter et al., 1978), synapses potentiated during the presentation of a stimulus satisfy the requirements for an engram candidate: they are activated by the occurrence of a stimulus, and they undergo modifications that change their response as a consequence of stimulus presentation. On a third point, i.e., if their reactivation can start the memory recall, a definitive answer is still lacking, although there is evidence pointing in its support (Nabavi et al., 2014; Abdou et al., 2018). 
In vivo potentiation is believed to recapitulate what happens during electrophysiological induction of LTP (Andersen et al., 2017). A cascade of events following glutamatergic stimulation involves a complicated intracellular signaling cascade, including $\alpha$ CaMKII phosphorylation and remodeling of the actin cytoskeleton (Herring and Nicoll, 2016). Two phases can be identified within LTP, namely, early (E-) and late (L-LTP; Mayford et al., 2012). E-LTP is a rapid increase in the efficiency of synaptic transmission and typically lasts a few hours or less, whereas L-LTP can last for several hours (Kelleher et al., 2004; Wang et al., 2010). E- and L-LTP should be regarded as two separate processes taking place at the same time, although they clearly interact with each other (Reymann and Frey, 2007; Bliss et al., 2018). E-LTP induction is not sensitive to translation inhibitors and is generally thought to be dependent on the exposure of more AMPA-sensitive glutamate receptors (AMPARs), whereas L-LTP expression and maintenance is translation dependent (Kelleher et al., 2004). The two forms are believed to have different intensity thresholds for induction, and L-LTP-like forms of potentiation can be even induced in the absence of E-LTP (Bliss et al., 2018), for example, through the activation of the BDNF/TrkB pathway (Kang and Schuman, 1996). Furthermore, multiple forms of LTP can co-exist within the same neuronal population, which may have different requirements in terms of molecular pathways involved (Edelmann et al., 2017).

Potentiation is usually accompanied by structural events, such as the enlargement of pre-existing synapses and the formation of new synapses. Matsuzaki et al. (2004) showed that inducing LTP at specific synapses causes an increase in spine volume, which is accompanied by an analogous increase in the dimension of the postsynaptic density (PSD; Meyer et al., 2014). Similarly, learning is accompanied by new spine formation and stabilization (Xu et al., 2009; Yang et al., 2009). These events are relatively simple to identify and follow over time, by expressing untargeted (Chen et al., 2000), membrane anchored (Cai et al., 2013), or postsynaptic fluorescent proteins that fill the neurons. However, absolute spine dimension or spine emergence is only quite an indirect proxy of the synapse status. Furthermore, spines are typically underresolved by standard imaging techniques-with the exception of super resolution imaging-which can make it harder to evaluate spine dimensions and to distinguish two spines in close proximity (Attardo et al., 2015; Pfeiffer et al., 2018).

\section{SYNAPTIC POTENTIATION REPORTERS: E-LTP}

During E-LTP, AMPARs are exocytosed onto the surface of the plasma membrane in proximity to the synapse, where they can diffuse in the lipid bilayer until they are captured and retained in the PSD by interactions with scaffold proteins, such as PSD95 (Chater and Goda, 2014). Initially designed to follow AMPAR mobility, fusion proteins between an AMPAR subunit and fluorescent EGFP later became reporters to identify activated synapses in the brain (Tanaka and Hirano, 2012). The most diffuse of such reporters is a fusion protein between the rat AMPAR subunit 1 (SEP-GluA1) and a $\mathrm{pH}$-sensitive EGFP variant, superecliptic pHluorin (SEP). SEP is inserted at the $\mathrm{N}$-terminus of the AMPAR subunit after the signal peptide, which faces the extracellular side of the plasma membrane. At physiological $\mathrm{pH}$, it displays bright green fluorescence, but it is severely quenched at acidic $\mathrm{pH}$, typical of the endosomal compartment (Kopec et al., 2006). This means that when AMPARs containing subunit 1 are exposed at the surface of the plasma membrane, these sites can be identified by changes in fluorescence.

When expressed in vivo in layer $2 / 3$ pyramidal neurons in the barrel cortex, SEP-GluA1 enabled the identification of synapses undergoing potentiation following whisker stimulation (Figure 1B; Makino and Malinow, 2011; Zhang et al., 2015). Two-photon imaging allowed the authors to map the position of potentiated synapses by looking at the accumulation of surface SEP-GluA1, showing that sensory stimulation causes clustering of synaptic upscaling (Makino and Malinow, 2011). The sensorydependent accumulation of SEP-GluA1 to synapses is dependent on NMDAR activity, since its antagonist CPP prevented the observed change in fluorescence. Notably, the observed increase in surface SEP-GluA1 after whisker stimulation is stable for up to $48 \mathrm{~h}$, and in some cases, SEP-GluA1 intensity could be identified reliably on the same spine for up to 28 days (Zhang et al., 2015).

GFP-tagged AMPAR subunit 1 has been used in conjunction with the Tet-tag system (Reijmers et al., 2007) to image active synapses in hippocampal CA1 neurons, during a time window controlled by doxycycline, of animals exploring a novel context (Takahashi et al., 2012) or undergoing contextual fear conditioning (Matsuo et al., 2008). The GFP-GluA1 ${ }^{+}$ synapses are particularly represented in mushroom spines after fear conditioning, which are usually considered more mature spines.

\section{Significance of AMPAR-Based Reporters}

While NMDA receptors are generally necessary for LTP induction in glutamatergic synapses, the recruitment of further AMPA receptors is responsible for the early increase in synaptic currents. Hence, synapses tagged with fluorescent AMPAR subunits are supposed to be the subset of synapses where activity reached the threshold to induce E-LTP. AMPARs containing only GluA1 subunits are preferentially recruited shortly after synaptic activity, whereas GluA2- and GluA3containing AMPAR incorporation only takes place at later times (Tanaka and Hirano, 2012; Diering and Huganir, 2018). Therefore, SEP-GluA1 containing spines likely represent the pool of synapses that underwent E-LTP-or received an equivalent physiological stimulation-a subset of those of course may also present L-LTP. Even if GluA2/3 containing synapses have been linked to a later stage of memory, such as consolidation and reconsolidation (Diering and Huganir, 2018; Shehata et al., 2018), it would be unclear then what a SEP-GluA2 (or SEP-GluA3) reporter could represent in terms of synaptic population, since SEP-GluA2 ${ }^{+}$synapses do not show analogous clustering to SEP-GluA1 ${ }^{+}$after whisker stimulation (Makino and Malinow, 2011). 
While the initial change in surface SEP-GluA1 is positively correlated with the increase in spine size in the first hour, on average, there was no lasting change of spine dimension (Zhang et al., 2015). This suggests that these synapses underwent only a transient increase in synaptic transmission. This does not preclude their identification even when potentiation has decayed: once incorporated in the pool of synaptic AMPARs, SEP-GluA1 molecules could be maintained as a lasting proportion of AMPARs, even when the overall number of AMPARs has returned to pre-stimulation levels. It is unclear what causes the retention of SEP signal even a month after whisker stimulation, since protein degradation likely eliminated SEP-GluA1 molecules that were initially incorporated; it is not clear how ongoing translation could maintain the asymmetric incorporation of new SEP-GluA1 between synapses.

\section{Technical Considerations}

SEP-GluA1 and GFP-GluA1 reporters for (E-)LTP can provide useful information in the identification of activated synapses. The use of SEP fusions rather than the GFP version reduces background from non-exposed AMPARs. However, loss of $\mathrm{pH}$ gradients after fixation makes the use of SEP-GluA1 only advantageous for live imaging experiments (Kopec et al., 2006); hence, it is usually limited to in vivo imaging of cortical areas through optical windows (Zhang et al., 2015) or acute slices (Makino and Malinow, 2011). Ex vivo analysis of fixed samples requires surface immunostaining of SEP/GFP-GluA1, which is facilitated by the generally good performance of anti-GFP antibodies, but is dependent on the fixation and antigen recognition conditions (Matsuo et al., 2008).

Furthermore, the use of SEP/GFP-GluA1 usually suffers from variable background signal, which is mostly due to the passive incorporation of the reporter GluA1 at synapses due to the normal turnover of AMPARs. In many cases, SEP-GluA1 incorporation is therefore expressed as change in intensity rather than absolute fluorescence (Araki et al., 2015; Zhang et al., 2015), which makes the identification of the subset of synapses involved in a given task trickier. In any case, restricting the temporal expression of the reporter, by controlling it with doxycycline or tamoxifen-sensitive Cre systems, can improve specificity and reduce background (Matsuo et al., 2008; Makino and Malinow, 2011).

\section{SYNAPTIC POTENTIATION REPORTERS AND EFFECTORS: L-LTP}

New translation is necessary for L-LTP (Kelleher et al., 2004), and protein synthesis from dendritically localized transcripts has been shown to be a key event following stimulations inducing L-LTP (Sutton and Schuman, 2006; Holt et al., 2019). Dendritic RNAs serve a number of purposes ranging from providing effector proteins (e.g., Arc, PKM $\zeta$, $\alpha$ CaMKII), producing key proteins for LTP expression (e.g., PSD95, GluA1), and supporting homeostatic protein turnover (Cajigas et al., 2012). Transcripts are transported and maintained in the dendrites in a translationally repressed state due to cis RNA sequences (elements allocated in the transcript as part of the ribonucleotide sequence) that are bound to molecular motors, regulatory proteins (e.g., FMRP), stalled components of the protein synthesis machine (e.g., CPEB, EJC proteins, PABP), miRNA, and other regulatory RNAs (Fernandez-Moya et al., 2014). A large number of RNAs are present in dendrites, with most of the containing dendritic targeting sequences (DTEs) in their $3^{\prime}$-UTR, specific sequences responsible for transport and regulation (Cajigas et al., 2012). Among them, the RNA of the IEG $\operatorname{arc}$ has been shown to rapidly and abundantly translocate in the dendritic layer after high-frequency stimulation of the dentate gyrus from the perforant path (PP), accumulating in correspondence to the activated synapses (Steward and Worley, 2001; Dynes and Steward, 2012; de Solis et al., 2017). Arc translation is induced by LTP stimuli and has been observed to occur in correspondence to dendritic synapses (Bramham et al., 2010; Minatohara et al., 2016; Na et al., 2016).

Two groups have used the properties conferred by arc untranslated regions (UTRs) to engineer protein reporters and actuators to be specifically translated at potentiated synapses (Hayashi-Takagi et al., 2015; Gobbo et al., 2017).

Hayashi-Takagi et al. (2015) generated AS-PARac1, a photoactivable Rac1-thanks to a photosensible LOV domain (Wu et al., 2009) - fused to a fluorescent protein, expressed from a mRNA that bears Arc dendritic targeting element (DTE; Kobayashi et al., 2005) in its $3^{\prime}$-UTR (Figure 1C). The DTE sequence conferred activity-dependent translation of the reporter protein, which was anchored at the postsynaptic membrane in the spine by a PSD-binding moiety consisting of a deletion mutant of PSD95 (PSD $\Delta 1,2$ ). AS-PARac1 labeled synapses sparsely when expressed in hippocampal organotypic cultures and in the motor cortex in vivo, and following a motor task training, the reporter preferentially labeled enlarged and newly formed spines. Focal LTP induced by glutamate uncaging resulted in the expression of AS-PARacl at stimulated synapses only, which was dependent on new protein synthesis. Therefore, the AS-PARac1 reporter allows mapping of the potentiated synapses. Notably, the AS-PARac1 reporter also allows intervention on the labeled synapses, since Rac1 is a small GTPase that regulates cytoskeleton organization. In the dark, the Rac1 activity of the AS-PARacl reporter protein, expressed at potentiated synapses, is inhibited by steric hindrance by the photosensible LOV domain, and a pulsed blue-light stimulation can remove the LOV block (Wu et al., 2009), depolymerizing the actin filaments inside synapses. This resulted in labeled spines to irreversibly collapse and shrink in dimension, and accordingly, synaptic transmission at these potentiated synapses appeared to be severely, if not completely, impaired.

Since AS-PARacl is a soluble protein, is it possible to express also membrane proteins, such as excitatory or inhibitory optogenetic channels at potentiated synapses? This would allow a functional and reversible modulation of the activity of synapses that had been potentiated by a previous learning activity. Gobbo et al. (2017) addressed this question by driving the expression of the ChR2 Channelrhodopsin variant (Gunaydin et al., 2010) from a vector harboring, in its $5^{\prime}$ - and $3^{\prime}$-UTR, RNA sequences derived from Arc UTRs (SA-Ch, brief for SynActive-ChR2; Figure 1D). These $5^{\prime}$ - and $3^{\prime}$-UTR sequences mediate the 
translation of the SA-Ch actuator and reporter at potentiated synapses. ChR2 was fused to the red fluorescent protein (RFP) mCherry and to a bi-partite tag at the C-terminus derived from the NMDAR C-terminus consensus sequence (Kornau et al., 1995; Gradinaru et al., 2007) that interacts with PSD components to localize the protein to the postsynaptic domain.

Under resting conditions, SA-Ch transcript is mainly silent, and only a percentage of synapses express SA-Ch. Translation of SA-Ch is increased by chemical LTP induction and is negligible when potentiation is suppressed when NMDAR signaling is blocked with AP5. LTP induction with glutamate uncaging causes the selective expression of $\mathrm{SA}-\mathrm{Ch}$ at the stimulated synapses, which is blocked by anisomycin application. When expressed in the hippocampus, spines were labeled by SA-Ch after animals explored a new environment. SA-Ch retains the basic properties of the encoded ChR2 variant (Gunaydin et al., 2010), and blue-light illumination is sufficient to drive synaptic events that are not dependent on presynaptic activity, as measured by light-evoked calcium transients. Light-activated SA-Ch mimics the physiology of synaptic activity, since synaptic, but not dendritic, illumination causes local calcium transients, and optogenetic stimulation initiates $\alpha$ CaMKII phosphorylation and accumulation at SA- $\mathrm{Ch}^{+}$synapses (Lisman et al., 2012).

\section{Significance of AS and SA Reporters}

The AS-PARacl and SA-Ch strategies are based on local translation at synapses undergoing LTP. Translation in dendrites is necessary for most L-LTP forms, and the local application of protein synthesis inhibitors to dendritic regions decreases L-LTP amplitude (Bradshaw et al., 2003). Moreover, the application of the inhibitor of protein synthesis emetine to the apical dendrites of hippocampal CA1 pyramidal neurons impairs L-LTP at apical but not basal dendrites. Both approaches rely on PSD-interacting moieties to localize the newly synthesized protein to the synapse and prevent its diffusion, exploiting what is likely to be a general mechanism for new proteins incorporation during the structural reorganization of synapses undergoing potentiation (Bosch et al., 2014).

The responsiveness to neuron activation is due to Arc UTRs, which regulate localization and expression (Pinkstaff et al., 2001; Kobayashi et al., 2005). Arc is rapidly expressed after neuron and synaptic activation by electroconvulsive seizures and PP high-frequency stimulation that induce LTP; the administration of the NMDAR blocker MK-801 blocks both LTP and Arc expression induction (Lyford et al., 1995). Novel Arc synthesis is necessary for induction and consolidation of LTP (Plath et al., 2006), and genetic or antisense Arc knock-out in mice and rats impairs L-LTP consolidation (Guzowski et al., 2000). Although ARC protein has been ascribed a complementary role in LTD and homeostatic scaling, in vivo stimulations at frequencies that induce LTD (e.g., $1 \mathrm{~Hz}$ ) do not initiate $A r c$ expression (Steward and Worley, 2001), and LTD induced by NMDA-only application does not induce Arc and does not require ARC protein (Bramham et al., 2010). Furthermore, acute Arc overexpression in vivo does not induce LTD (Bramham et al., 2010; Yilmaz-Rastoder et al., 2011); rather, ARC may have a priming effect on synapses (Jakkamsetti et al., 2013). A possibility is that, following LTP induction, ARC protein acts locally to mobilize AMPAR for L-LTP consolidation (Hanley, 2014), thus explaining its accumulation in inactive synapses following LTP-inducing BDNF administration (Okuno et al., 2012). In line with this interpretation, shRNA Arc knockdown increases the spreading of SEP-tagged AMPAR to spines surrounding synapses undergoing structural LTP (El-Boustani et al., 2018).

Both AS-PaRac1 and SA-Ch are synthesized following focal LTP protocols, and their expression positively correlates with SEP-GluA1 accumulation and spine dimension (both mRFP and mTurquoise fluorophore have been used in place of the Venus moiety; Hayashi-Takagi et al., 2015; Gobbo et al., 2017). Notably, a proportion of SEP-GluA1 containing synapses does not express SA-Ch, suggesting that in this population of synapses, the threshold for long-lasting potentiation was not reached; consistently, in this group, SEP-GluA1 intensity levels were lower than in the SA-Ch+ ${ }^{+}$group (Gobbo et al., 2017). Thus, the tagged population of synapses is the ensemble of synapses undergoing translation dependent long-term potentiation, consistently with the in vivo reports. In particular, Hayashi-Takagi et al. (2015) found that following the optogenetic ablation of the synapses tagged in the motor cortex during the learning of a motor task severely impaired the performance of the animals.

\section{Technical Considerations}

The AS-PARacl and SA-Ch reporters provide both live and remote access to the population of potentiated synapses during the expression of the corresponding transcripts, making them suitable for imaging in living animals (taking into account the protein synthesis time and the maturation time of the fluorophore in the fluorescent protein of the reporter) and in fixed brains. AS-PaRac1 relies to ongoing degradation conferred by the PSD $\Delta 1,2$ component that also reduces the half-life of the reporter to 1 or 2 days, making it possible to conduct longitudinal imaging studies even with a constitutive promoter (HayashiTakagi et al., 2015).

SA-Ch appears to rely more heavily on translation regulation, conferred by the presence of a larger portion of the Arc 3'-UTR and, particularly, of the Arc 5'-UTR, which uses a non-canonical, IRES-dependent mechanism of translation (Gobbo et al., 2017). Indeed, Hayashi-Takagi et al. (2015) also observed increased specificity when using the synthetic SARE promoter (Kawashima et al., 2013) rather than the constitutive CAG promoter; indeed, the use of SARE promoter results in the incorporation of part of the Arc 5'-UTR in the final AS-PARac1 transcript. Nevertheless, to increase the time resolution to tag and identify potentiated synapses, the use of inducible systems can help, as done for activity tagging of neurons (Reijmers et al., 2007; Kawashima et al., 2014). For example, Hayashi-Takagi et al. (2015) used a synthetic activity-dependent promoter, whereas Gobbo et al. (2017) used a doxycycline-sensitive promoter to initiate the production of the SA-Ch transcript, hence defining the time window for tagging by means of the drug administration.

Although originally developed to express effectors at potentiated synapses, the AS-PARacl and SA-Ch systems seem flexible enough to express different proteins by changing the cDNA sequence that will be translated into protein. Indeed, the 
two groups have shown that at least to some extent, the reporters can be modified and transformed into mapping instruments, removing the active component (i.e., Rac1 or the ChR 2 moieties) and changing the fluorescent protein to solve spectral issues when imaging (Hayashi-Takagi et al., 2015; Gobbo et al., 2017). For instance, the SynActive vectors, which use the expression cassette of SA-Ch, are being used to drive the expression of proteomic bait reporters, to study the molecular composition of potentiated spines (Mainardi et al., 2018).

\section{Other Reporters}

Other groups have developed reporters for local dendritic translations; however, their focus has mainly relied on gaining insight into the regulation of the expression of particular genes or the effect of specific RNA sequences (Aakalu et al., 2001; Butko et al., 2012; Ifrim et al., 2015). For those interested in a comprehensive evaluation of these reporters, we refer to other excellent reviews (Biever et al., 2019; Holt et al., 2019).

\section{SYNAPTIC CONNECTIVITY}

Multiple inputs converge onto the same postsynaptic neurons, and identifying which connections are active during experiences and learning can provide crucial information about the flux of information. This is particularly important when the circuit is not entirely described, or when relevant connections represent only one of many possibilities of pairwise links (as for example in the hippocampal formation). One possibility is to image live synaptic activity of both pre- and postsynaptic neurons, e.g., with GECIs of different colors. For example, Inoue et al. (2019) expressed the red fluorescent XCaMP-R in layer 5 pyramidal neurons and the yellow XCaMP-Y in somatostatin interneurons to detect concomitant synaptic activity in the barrel cortex. This could be potentially extended to synaptic connections between various neurons, either different neuron types or neurons whose soma is located in different brain areas. This could be potentially restricted between engram cell populations forming monosynaptic connections (e.g., CA1-subiculum or PFC-BLA connections) by expressing spectrally distinct GECIs in the two populations with activity tagging technologies.

This conceptual approach has been undertaken by Choi et al. (2018) to visualize connections between CA3 and CA1 engram cells. They adapted the mGRASP technology, which was designed to map synaptic connections between neurons by means of split GFP complementation: the two halves (pre- and post-GRASP) are exposed on the surface of the pre- and postsynaptic neurons separately by fusing it to a transmembrane domain. Only at synaptic interfaces the two halves are at the right distance to reconstruct the full, fluorescent, GFP protein (Kim et al., 2011). Choi et al. (2018) derived cyan and yellow pre-mGRASP variants and expressed them in CA3 constitutively (cyan) from the cfos/tTA activity tagging system (yellow; Garner et al., 2012). Similarly, they expressed the post-mGRASP in CA1 neurons, along with a RFP from a constitutive promoter and a far-RFP in an activity dependent way. Thus, connections between CA3 and CA1 engram cells, as well as the other combinations, can be identified as yellow synapses on far-red CA1 neurons. This enabled the authors to measure morphological and physiological properties of this set of synapses, demonstrating that synapses between CA3 and CA1 engram cells display several potentiation hallmarks. The work by Choi et al. (2018) was actually preceded by Macpherson et al. (2015), who developed a three color variant of the GRASP system. Here, $\operatorname{splGFP}(1-10$; corresponding to pre-GRASP $)$ is fused to synaptobrevin, a protein localized to presynaptic vesicles; hence, when neuronal activity causes the fusion of neurotransmitter vesicles, spl-GFP(1-10) is exposed on the presynaptic membrane. This causes an increase in fluorescence when postsynaptic partners meet, and the activation of multiple pathways has been studied to the Drosophila olfactory and thermosensory system using different color variants of this system (Macpherson et al., 2015).

Multiple methods can in principle be combined to gather information about the synapse status and the relative connectivity. In its simplest form, the postsynaptic markers of activity described in the previous sections can be expressed in one region or neuron population, and axons or terminals of different neurons can be labeled expressing a spectrally distinct fluorescent protein. For example, a red AS-PARac1 variant was expressed along with a GFP filler and a blue presynaptic marker (VAMP2-Turquoise) to mark reciprocal connections within the same populations of cortical neurons (Hoshiba et al., 2017). Even if in this proof-of-principle all of the constructs are expressed in the same neurons, it also seems straightforward to express the two transgenes to different pre- and postsynaptic populations. A recent technique named SYNPLA can also be useful to inquire connections between neuronal populations. SYNPLA detects recently activated GluA1-positive synapses by fusing the myc peptide to the extracellular side of presynaptic neurexin; using a combination of oligonucleotide-bound antibodies, rolling circle amplification, and fluorescent nucleotides, it detects juxtaposed myc-neurexin and newly exposed GluA1 as very bright spots (Dore et al., 2020).

\section{Technical Considerations}

Activity-dependent synaptic tracing methods are new technologies that have the potential to provide insight into the activity and plasticity of connections between brain areas as well as local circuits. Of course, when coupling reporters of postsynaptic activity with projection tracers, the same technical considerations hold as if they were used alone. In addition, the combination of techniques calls for a careful evaluation of the imaging and detection conditions, as the crowding of the spectral window increases with the number of different fluorophores; realistically, information about synaptic connectivity in an activity-dependent manner would require three or four different fluorophores. While this is technically feasible, care is advised in order to reduce spectral crosstalk, especially if weak signal is involved, or significant differences in signal intensity are at play. In some cases, the use of reporter variants optimized for orthogonal and high signal-to-background ratio when immunodetected could provide significant advantages (Viswanathan et al., 2015; Gao et al., 2019). Particular care during imaging and image reconstruction would be needed 
to ensure that optical aberrations are minimized, which could otherwise result in images misalignment and potential identification errors.

\section{SYNAPSE CLUSTERS}

In the previous sections, we have summarized the various approaches that can be used to identify ensembles of synapses involved in particular neural representations. The degree of convergence of the various methods is unclear, similarly to what also happens with cellular tagging (Guenthner et al., 2013; Ramirez et al., 2013; Wang et al., 2017). Nevertheless, a degree of overlap between active synapses, synapses exposing new AMPA receptors, and synapses identified by AS-PARac1 and SA-Ch translation reporters is expected, according to the general understanding of the mechanisms of potentiation (Bliss et al., 2018). For example, both AS-PARacl and SA-Ch expression correlates with SEP-GluA1 exposure in most synapses.

Notably, many groups have independently reported spatial clustering of synaptic activity, regardless of the detection methods used. Kleindienst et al. (2011) have reported clustering of coincident activity of synapses on CA3 dendrites in cultured slices, with higher co-activation likelihood at intersynaptic distances smaller than $16 \mu \mathrm{m}$. Similarly, Takahashi et al. (2012) found clusters of 2-12 co-active synapses performing calcium imaging in CA1 neurons. In vivo, clusters of co-active synapses have been detected in the layer $2 / 3$ pyramidal neuron of the somatosensory cortex (Takahashi et al., 2012) and in layer $2 / 3$ and 5 of the visual cortex (Winnubst et al., 2015; Gökçe et al., 2016) with similar distances. In an analogous way, clustering among synapses incorporating GFP-tagged GluA1 has been shown in the barrel cortex (Makino and Malinow, 2011) and in the hippocampus CA1, with typical cluster dimensions around $8 \mu \mathrm{m}$ (Takahashi et al., 2012). Observing SA-Ch expression, Gobbo et al. (2017) demonstrated preferential clustering of potentiated synapses in both the dentate gyrus and CA1 hippocampal region, with clusters typically containing 2-14 synapses. Such consistency, in terms of number of synapses involved and of intersynaptic distance, is likely to underlie some mutual dependency of the clustered synapses (Figure 2).

Synaptic capture (STC) is a cellular mechanism whereby a weak stimulation, which normally would lead to E-LTP, results in L-LTP if a strong stimulation is applied, within an hour, to a different synapse onto the same pool of neurons. STC is thought to be due, in part, to the generation of diffusible signals (e.g., proteins) from the synapses receiving the strong stimulation. Consistently with the ranges reported above, $10 \mu \mathrm{m}$ is the threshold distance found for a subthreshold stimulation to induce potentiation when paired to strong stimulation of another synapse at a given position (Harvey and Svoboda, 2007), and NMDAR inhibition with AP5 suppresses clustered co-activity (Takahashi et al., 2012). Similarly, another group found that STC can take place within $30 \mu \mathrm{m}$ of the tetanized synapse, dropping to zero when the distance between the two spines is $70 \mu \mathrm{m}$ (Govindarajan et al., 2006). This suggests that clusters of potentiated synapses are linked to mechanisms

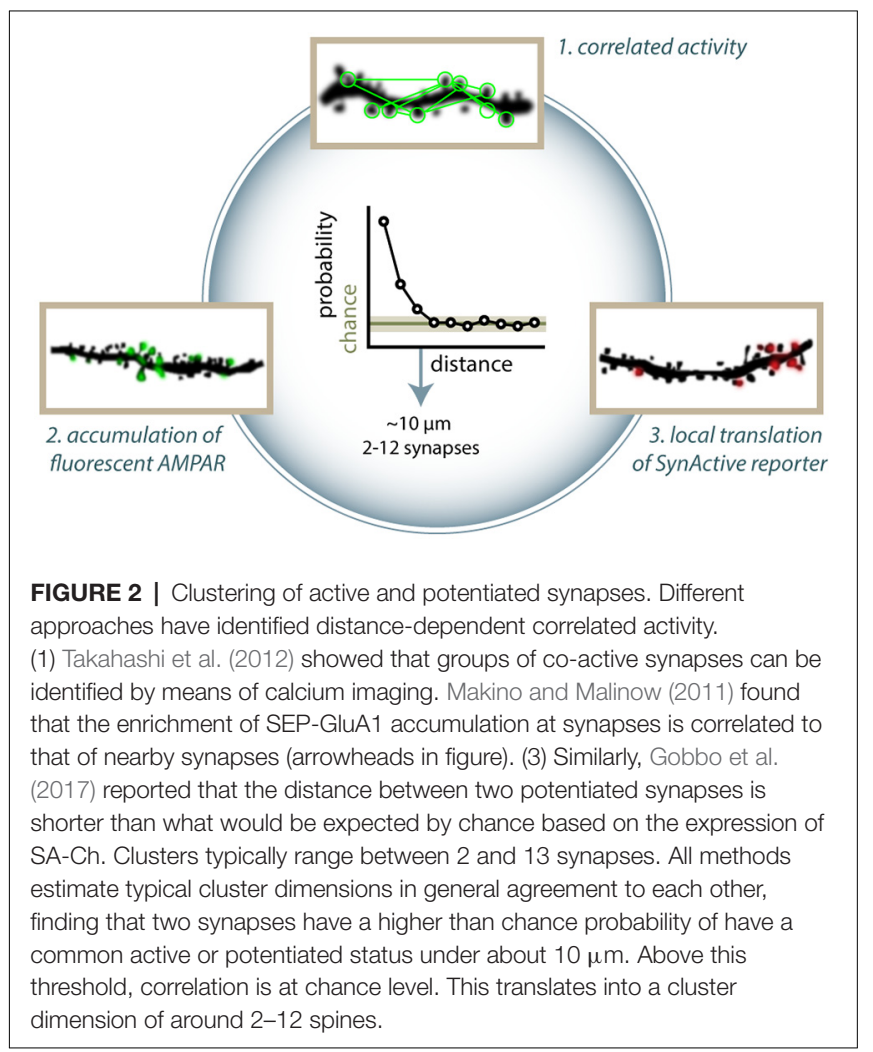

of synaptic cooperativity. Nonlinear properties of neuronal activity, diffusion of intracellular effectors, or anatomical clustering of inputs could explain this effect (Kastellakis et al., 2015). Regardless of the mechanism, clustering can have a profound impact on memory encoding (Mikhaylova and Kreutz, 2018), facilitating the response to a given stimulus or the encoding of a unitary piece of representation from converging inputs (Winnubst and Lohmann, 2012; Kastellakis et al., 2015). Clustering of potentiated inputs could be a mechanism employed by neurons to store information and facilitate recall, with the additional property of being more robust toward the loss of synapses and transmission noise. Indeed, it has been shown that learning facilitates the formation of new spines in clusters in the retrosplenial cortex (Frank et al., 2018), and LTP induction extends significantly the lifetime of synapses within $5 \mu \mathrm{m}$ from a potentiated synapse (Wiegert et al., 2018).

\section{INHIBITORY SYNAPSES}

The wary reader will have noticed by now that all the reporters we have described so far identify glutamatergic synapses, which almost invariably correspond to particular structures of the postsynaptic neuron, the spines (Holtmaat and Svoboda, 2009). Nonetheless, inhibitory neurons constitute a small (10-15\%) but significant proportion of neurons in the brain (Tremblay et al., 2016) and play a fundamental role in information processing in the brain (Müllner et al., 2015). Inhibitory transmission onto excitatory neurons can undergo activity-dependent plasticity 
(Fagiolini et al., 1994; Hartman et al., 2006; Chiu et al., 2019), which can shape excitatory transmission (Lin et al., 2008; Chevaleyre and Piskorowski, 2014). Inhibitory neurons may even establish complementary ensembles of neurons modulating the activity of ensembles of pyramidal cellular engrams, which may have a compensatory effect to restore the excitation/inhibition balance, contribute to stimulus filtering (for example, in the representation of familiar situations), or act in synergy with principal (excitatory) engrams in context discrimination (Barron et al., 2017). However, studies focused on imaging inhibitory synapses plasticity have been limited for a number of reasons.

First, GABAergic synapses are harder to identify than glutamatergic ones from the morphological point of view, as there is no obvious structural correlate analogous to excitatory synapses, and inhibitory synapses are identified both on dendritic shafts and on the sides of spines, which also contain excitatory synapses (Chen et al., 2012). Hence, inhibitory plasticity can generally be inferred only by the remodeling of the axonal bouton (Wierenga et al., 2008; Keck et al., 2011). An alternative consists in the identification of inhibitory synapses with fluorescent proteins fused to gephyrin, a postsynaptic scaffold protein found at inhibitory synapses (Triller et al., 1985). With Teal-gephyrin, a cyan version of gephyrin, Chen et al. (2012) were able to describe the dynamics of the plasticity of inhibitory synapses in layer $2 / 3$ pyramidal neurons in the visual cortex across days, showing that spine-associated inhibitory synapses are more dynamic than those located on the dendritic shafts. Furthermore, visual experience induces a spatially clustered reorganization of inhibitory synapses in correspondence to dynamic spines, suggesting that inhibitory and excitatory plasticity are correlated (Chen et al., 2011; Villa et al., 2016).

Second, inhibitory plasticity is less characterized than excitatory synapses (Kano, 1995; Castillo et al., 2011; Flores and Méndez, 2014), not least because of the plethora of plasticity forms (Maffei, 2011; Chiu et al., 2019) and of diverse interneuron populations (Kubota et al., 2016; Tremblay et al., 2016; Pelkey et al., 2017). In any case, it is difficult to image inhibitory activity and plasticity. Inhibitory activity can be inferred by recording the activity of presynaptic boutons with GECIs (Inoue et al., 2019). Theoretically, inhibition could be imaged with voltage sensors (Canepari et al., 2010) or with chloride sensors to identify the flux of $\mathrm{Cl}^{-}$ions from $\mathrm{GABA}_{\mathrm{A}}$ channels. However, the two latest available chloride sensors, Chlomeleon (Grimley et al., 2013) and Chlophensor (Sato et al., 2017), are generally used to image whole neuron chloride dynamics, and they have not been shown to be usable at synaptic resolution. In addition, inhibitory synaptic transmission does not always result in chloride influx and could act in the form of shunting inhibition. Lastly, the recent iGABASnFR, analogous to the glutamate sensor iGluSnFR, signals gamma aminobutyric acid (GABA) binding with an increase in green fluorescence (Marvin et al., 2019). Starting from candidate GABA-binding proteins identified with genomic mining in the bacteria gene pool, the authors inserted cpEGFP in their sequences and came up with a few candidate GABA sensors. Although it might constitute a solid stepping stone, iGABASnFR still does not appear powerful enough to image inhibitory activity at the single-synapse level.

\section{EXTENDING THE TOOLBOX}

\section{Neuromodulators}

Besides glutamate and GABA, other neurotransmitters and neuromodulators may have profound effects on neural activity and information processing. Furthermore, neuromodulators can modify the plasticity properties of synapses, e.g., by lowering the threshold to produce potentiation at synapses (Takeuchi et al., 2016). In recent years, genetic sensors for modulators, such as dopamine, norepinephrine, and others, have been reported. While they have been shown to detect neuromodulators release in vivo, their relatively low fluorescence has so far limited their use to whole-cell applications (Leopold et al., 2019). Hence, they do not seem to detect the release of neuromodulators at single synapses or release terminals. Nonetheless, continuous improvements of the most promising variants could produce in the near future sensors able to detect the release of dopamine and other modulators with single-synapse resolution.

\section{Inhibitory Neurons}

Most of the imaging applications of synaptic activity have been conducted in excitatory neurons, either pyramidal neurons in the cortex and the hippocampus or granule cells in the dentate gyrus. Notably, inhibitory neurons undergo synaptic plasticity too (Chen et al., 2013; He et al., 2016; Feese et al., 2018), and sensory activity shapes the plasticity of neural inhibition (Fagiolini et al., 1994). While calcium imaging of synaptic transmission has been successfully performed also in inhibitory neurons (Chen et al., 2013), it is unclear how the reporters for synaptic potentiation would perform in GABAergic neurons, also considering that a great percentage of these neurons do not display spines (Scheuss and Bonhoeffer, 2014; Pelkey et al., 2017).

\section{Other Forms of Plasticity}

Potentiation of synaptic transmission is a major topic in memory research, which could explain why the development of tools to visualize synaptic plasticity has been focused on LTP reporters. Indeed, LTP and LTD can bi-directionally modulate both the amplitude of synaptic responses and memory performance (Collingridge et al., 2010; Nabavi et al., 2014). LTD is generally elicited by low-frequency stimulations, although other forms exist, and shares a significant proportion of the molecules involved in LTP, which, along with the fact of being somewhat less characterized than LTP at the molecular level, probably explains the lack of LTD-selective sensors (Kemp and ManahanVaughan, 2007). Indeed, some molecules including betaCaMKII and phosphatases, such as PP1, seem to be crucial in establishing LTD and could be helpful in the design of LTD sensors.

Because LTD typically results in the removal of AMPAR from the surface of depotentiated synapses, some of the tools used to monitor potentiation could be used in principle to also detect LTD. Indeed, a SEP-fused AMPA receptor subunit 2 (SEP-GluA2) is internalized in response to LTD induction, even though this has not been tested in vivo yet (Ashby et al., 2004). Analogously to LTP, synaptic LTD could be inferred by synaptic shrinkage or elimination using diffusible cell fillers; functional LTD and depotentiation could be inferred using GECIs from a decrease in the amplitude of $\Delta \mathrm{F} / \mathrm{F}$ synaptic events 
(Wiegert et al., 2018). Reducing synaptic transmission at the olfactory glomeruli in Drosophila using temperature-sensitive mutants showed reduced postsynaptic $\Delta \mathrm{F} / \mathrm{F}$ events measured with a postsynaptic localized dHomer-GCaMP3 fusion, although longitudinal changes have not been measured (Pech et al., 2015).

Besides the Hebbian form of plasticity, such as LTP and LTD, other forms of plasticity have been described. For instance, metaplasticity has been described as a mechanism whereby prior plasticity at a particular synapse modifies the response to subsequent stimulations compared with naïve synapses and can assume the form of a change in threshold, amplitude, or even direction of change (increase or decrease in amplitude; Abraham, 2008). Homeostatic plasticity generally occurs on longer timescales and has a net effect of counterbalancing changes in activity that drives the system away from an equilibrium point, e.g., reducing neuron excitability after sustained incoming activity (Turrigiano, 2017). Furthermore, both homosynaptic and heterosynaptic forms of plasticity exist, as well as forms of circuit plasticity. Overall, these mechanisms are less understood at a molecular level and share a significant proportion of the molecules involved in LTP and LTD. Nonetheless, some of the tools to image synaptic activity could find application to these forms of plasticity. Where AMPA receptors insertion or removal from the plasma membrane is involved, SEP-GluA sensors could be used as indicators. Different forms of homeostatic plasticity have been reported to act either by modifying the postsynaptic response to a release of a quantum of neurotransmitter or by changing the probability of released neurotransmitter. Therefore, GECIs and pHluorin-based sensors could find application in monitoring changes in calcium influx at the pre- or postsynaptic terminal or in the rate of vesicle fusion with the presynaptic membrane. Indeed, Pech et al. (2015) employed the presynaptic $\mathrm{pH}$-sensitive synaptophysin-pHTomato and the postsynaptic dHomer-GCaMP3 to demonstrate that prolonged exposure of Drosophila flies to apple odor over multiple days causes a reduction in postsynaptic response, but not of presynaptic vesicle fusion, in the olfactory projecting neurons in the antennal lobe.

\section{REPORTERS AND EFFECTORS IN SYNAPTIC ENGRAM RESEARCH}

As we have discussed in the previous sections, the idea that synaptic engrams underlie the formation and maturation of cellular engrams is still to some extent an untested idea, despite the large amount of correlative evidence linking memory formation and synaptic potentiation (Takeuchi et al., 2014; Nomoto and Inokuchi, 2018). Indeed, the merge of two unitary cell engrams in a behaviorally relevant framework by means of their concomitant optogenetic reactivation is dependent on NMDAR activation and novel protein synthesis (Ohkawa et al., 2015), and anisomycin administration during memory encoding impairs the reactivation of the cellular engram by natural stimuli (Ryan et al., 2015). Indeed, spatial memories can also be formed in the absence of neural activity, but are dependent on NMDAR activity (Rossato et al., 2018). Hence, there is still considerable debate regarding the role of potentiated synapses in the establishment, storage, and recall of memories (Tonegawa et al., 2015b; Poo et al., 2016). While some argue that synapses and their modifications may be too short lived to provide a reliable substrate for memory (Mongillo et al., 2017), synaptic engrams could still support the representation of memories on shorterthan-lifetime timescales. Indeed, the half-life of hippocampal synapses has been reported to be surprisingly short (Attardo et al., 2015), but this could mirror the fact that the remote memories are less sensitive to hippocampal lesion or inactivation than recent memories (Squire, 1986; Squire et al., 2015; Kitamura et al., 2017). Cortical synapses have a significantly longer half-life (Yang et al., 2009; Attardo et al., 2015), and synapses tend to be more stable and last longer than other connections (Wiegert et al., 2018). In addition, the redundancy of synaptic engrams could make them robust toward noise in activity and loss of synapses, and multiple events of reconsolidation could support both the maintenance and flexibility of synaptic engrams, analogously to what happens with memories (Dudai, 2011).

Similar controversies about the existence of cellular engrams were solved with the development of new molecular tagging techniques (Eichenbaum, 2016). Given the properties of memory and potentiation, there is no need to exclude a priori a role of synaptic engrams in the formation and maturation of cellular engrams or even an interplay between synaptic and cellular engrams (Dudai and Morris, 2013). We believe that the use of the reporters and effectors we have described could contribute to solve at least some of the questions regarding the relative role of synaptic and cellular engrams. For instance, describing the relative allocation of active synapses and potentiated synapses between engram and non-engram cells could provide meaningful insight into the interplay between synaptic and cellular activity in memory paradigms. For example, it has been shown that the connections between CA3 and CA1 engram cells have a higher overall amplitude, and electrical LTP is occluded at these synapses, suggesting that potentiation had occurred at these synapses (Choi et al., 2018).

\section{Disrupting and Recalling Activity at Potentiated Synapses}

Testing the role of potentiated synapses in loss- or gain-offunction experiments could be performed by inhibiting or recalling the activity of potentiated synapses. If a given ensemble of synapses potentiated during a learning paradigm is relevant for the representation and storage of its memory, manipulating the activity of this synaptic ensemble should have a coherent effect on memory recall. Hayashi-Takagi et al. (2015) showed that a task-specific representation can occur at the synaptic level. Using the catalytic properties of AS-PARac1, they first trained the animal in a motor task (rotarod), then they optogenetically wiped out the potentiated synapses expressing AS-PARac1. As a result, the motor memory the animals had acquired was de facto erased (Figure 3A). Importantly, the performance in a previously learned different task was unaffected, demonstrating the specificity of the synaptic representation of the motor memory. These findings show that potentiated synapses play a role in the representation of a motor memory in the 


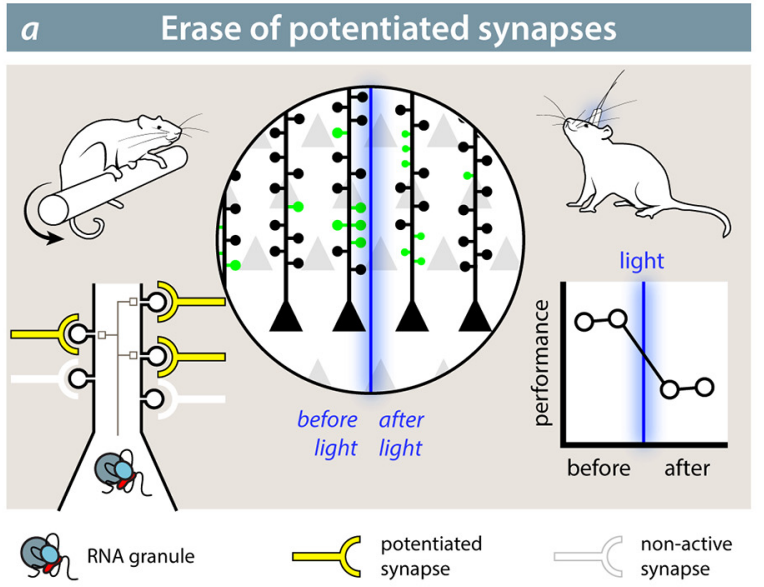

\section{b Reactivation of potentiated synapses}

\section{c Instating LTP in a subset of previously active synapses}
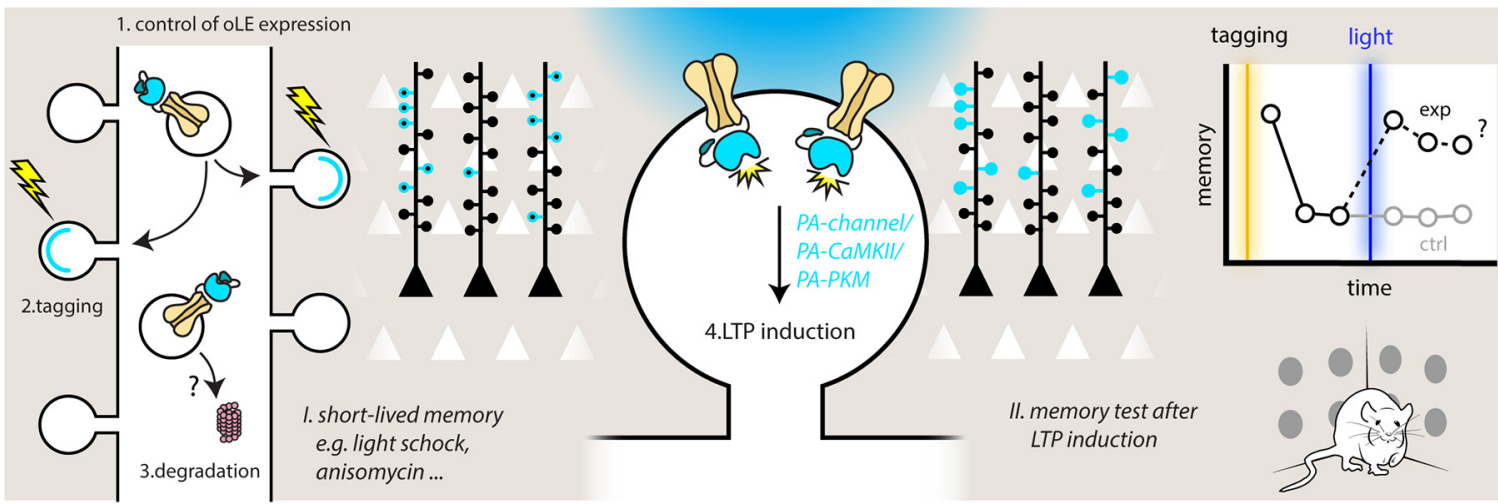

activated synapses

$\iint$ AMPAR-bound optogenetic LTP effector (oLE)
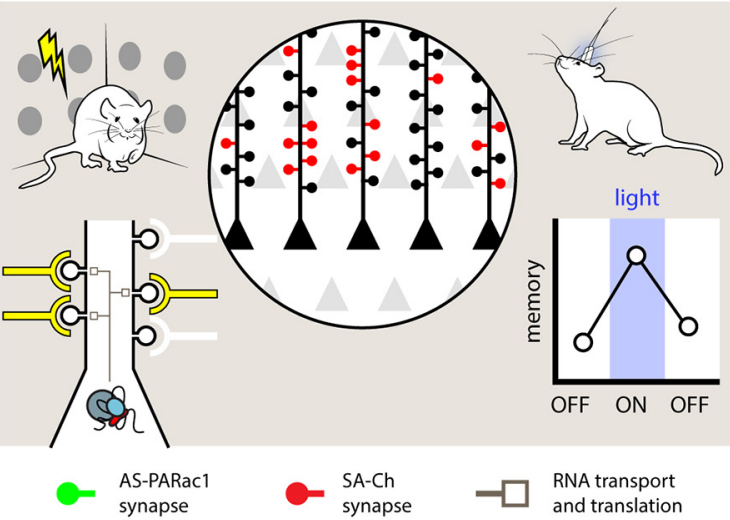

transport and translation with no lasting potentiation

\section{d Instating LTP in a subset of previously active synapses}

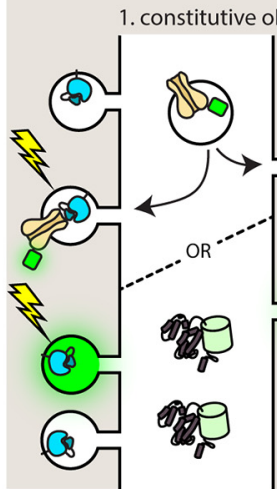

activated synapses with no lasting potentiation

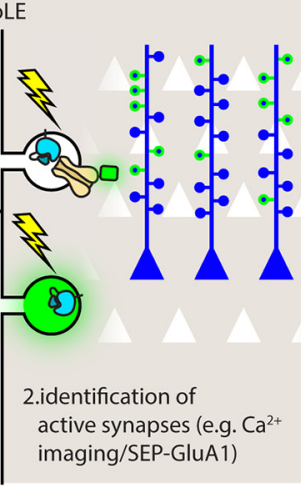
1 synapse localised
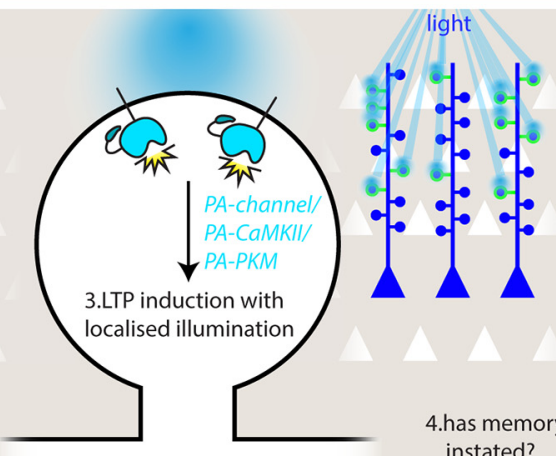

4.has memory being instated? imaging light

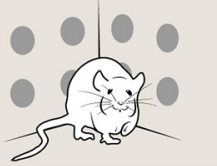

oLE-tagged synapse 
FIGURE 3 | Continued

prominent role in LTP, i.e., PKM light-sensitive NMDAR channels. To control their activity, a light-sensitive form of the two kinases has to be devised. The animal is first trained under conditions that do not form a long-lasting memory and/or impede potentiation; for example, a weak training, such as mild-shock contextual fear conditioning, anisomycin infusion, etc. In (C), the oLE localization to relevant synapses is achieved by fusing it to a GluA1 subunit, and it is coupled to AMPAR exposure. Control of expression would be critical, but specificity could be improved by increased degradation. If the interpretation of the role of LTP is correct, induction of LTP at this set of synapses would cause the formation of a memory. In (D), the opto-LTP effector is present at all synapses. The experimenter first detects active synapses by means of an imaging reporter (calcium imaging or visualization of SEP-GluA1, for example), then selectively activates the oLE at the selected synapses with patterned illumination.

cortex. AS-PARac1 only provides unidirectional manipulations of synaptic activity, since disrupting the spine structure is not reversible.

Conversely, after tagging potentiated synapses during the learning phase, SA-Ch expression at potentiated synapses could be used to recall their activity at a later stage, thus observing if their reactivation is sufficient to recall the encoded memory (Figure 3B; Gobbo et al., 2017). Although the synaptic events elicited by the optogenetic activation of SA-Ch are smaller in amplitude than the spontaneous ones from neurotransmitter release, this is likely due to the ChR2 variant employed (ChETA), which has rather small photocurrents compared with other ChR2 variants (Mattis et al., 2011). Given that most ChR2 differ from each other by a handful of point mutations, changing the ChETA moiety with a ChR2 with larger photocurrents (Dawydow et al., 2014) should be sufficient to match postsynaptic events, while maintaining the same pattern of expression as SA-Ch. Alternatively, single channel chemogenetic tools could be expressed at potentiated synapse, making it possible to re-excite potentiated synapses in larger brain volumes (Magnus et al., 2011). In principle, then, also inhibitory ChR2 variants or hyperpolarizing ion pumps could be expressed at potentiated synapses to inhibit synaptic activity reversibly (Wiegert et al., 2017).

\section{Instating Synaptic Plasticity at Synapses}

To probe the causal role of potentiation, one would need to artificially induce LTP on a set of synapses activated by a stimulus and observe if this results in the creation of a memory, thus mimicking a learned response to the very stimulus. The difference with the previous experiments (i.e., gain- and lossof-function alterations of the activity of potentiated synapses) is conceptual, and it is analogue to the difference existing between the tag-and-recall experiments on engram neurons (Liu et al., 2012; Ramirez et al., 2013) and the experiments performed by the Silva and Josselyn groups, where they skewed the probability of a subset of neurons to allocate a memory by CREB overexpression in those neurons (Han et al., 2009; Kim et al., 2014).

Testing the prediction that LTP at a given set of synapses is sufficient for engram formation has been originally proposed with a Gedankexperiment by Richard Morris (Takeuchi et al., 2014); how to actually implement it is a different story, and the author themselves breeze through the issue assuming a hypothetical light-sensitive calcium channel equipped with a tagged synapse-targeting sequence. The first, and crucial, step would be to identify or tag the synapses that are active during the presentation of the stimulus. This would need to happen under conditions that do not result in synapse potentiation (e.g., a subthreshold stimulation, a weak behavior paradigm, anisomycin infusion) and do not create a lasting memory. If memory were reinstated after artificially inducing LTP at these synapses, it would provide a definitive demonstration of the causal role of potentiation in memory. The conundrum lies in how to actually implement this with the available (or, at least, plausible) molecular tools.

The optogenetic LTP effector (oLE) would need to act on a signaling cascade that causes synaptic potentiation, but should be normally present-or recruited-at synapses in an inactive form. Theoretical but plausible candidates are constitutively active forms of $\alpha$ CaMKII (Lledo et al., 1995) or PKM $\zeta$ (Ron et al., 2011; Schuette et al., 2016), whose activity is hindered by a lightsensitive LOV domain, an approach employed by a number of gated enzymes, including PARac1 (Leopold et al., 2018). Light stimulation removes the steric block of the LOV domain, activating the enzyme. Notably, a light-sensible form of PKA already exists (O'Banion et al., 2018), and optogenetic inhibition of $\alpha$ CaMKII activity has already been successfully performed, suggesting that potentiation is necessary for memory formation (Murakoshi et al., 2017). Alternatively, the oLE could be a membrane $\mathrm{Ca}^{2+}$ channel: for instance, the LiGluN2A(V713C), a light-gated NMDAR, can induce structural and functional potentiation after single-spine optogenetic activation when supplemented with a photo-switchable azobenzene compound (Berlin et al., 2016).

To restrict its activity to the relevant synapses, the oLE could be fused to the intracellular terminus of SEP-GluA1like reporters, which are exposed at synapses during E-LTP, either at the C-terminus (LOV-gated enzymes) or as tandem transmembrane protein (light-sensitive NMDAR; Figure 3C). This would ensure that the oLE is only recruited in a subset of synapses along with SEP-GluA1; hence, LTP could be induced selectively with wide field illumination using standard optic fibers. Background could be reduced with inducible expression system or by active degradation of the extrasynaptic pool. Alternatively, specificity can be obtained by restricting the illumination to the desired subset of synapses even if the oLE is present at all postsynaptic sites (Figure 3D). First, relevant synapses are identified by means of calcium imaging or other activity reporters (e.g., SEP-GluA1), and their position annotated. Then, the oLE is activated by means of two-photon or holographic laser stimulation (Reutsky-Gefen et al., 2013). To avoid spectral crosstalk, GECIs with longer wavelength absorption (Inoue et al., 2019) or red pH-sensitive fluorescent proteins (Shen et al., 2014) can be used, since LOV-based optogenetic switches are usually blue-light sensitive. While theoretical, the described oLE would provide great insight into the exact role of synaptic activity and plasticity in memory, extending all-optical read-and-reactivate technologies already available at the whole neuron level (Marshel et al., 2019). 


\section{CONCLUSIONS}

In this article, we have tried our best to present in a systematic way the available technologies that allow to image synaptic activity and plasticity. This includes reporters to map and identify active and potentiated synapses and proteins that can recall or hinder synaptic activity.

The introduction of new molecular techniques, such as activity tagging of neurons, has caused a small revolution in the field on neuroscience. Similarly, employing techniques to address the role of subcellular compartments could expand our knowledge of brain functions and of the representation of memories. Being able to identify cells that encode a specific memory is undoubtedly one of the great achievements of modern neuroscience, shining light onto century-old questions (Schacter et al., 1978; Josselyn et al., 2017). However, the role of synaptic potentiation still does not fit smoothly in the picture, and the interplay between synaptic plasticity and cellular engrams is still unclear ( $\mathrm{Poo}$ et al., 2016). This also reflects on the open questions regarding how engram cells wire together to form a unitary ensemble, and how single, unitary ensembles-which could represent different components of a complex memory, e.g., the spatial information, the emotional value, etc.- - are merged together to form a unitary overall representation (Morris, 2003; Mayford et al., 2012; Eichenbaum, 2016).

The emergence of recent articles directly addressing the role of synaptic potentiation in the framework of cellular engrams and the plasticity of these cell ensembles (Ryan et al., 2015; Abdou et al., 2018; Rossato et al., 2018; Ghandour et al., 2019) demonstrates the renewed interest in synaptic plasticity. After the "golden era" of LTP (Bliss and Lømo, 1973; Collingridge et al., 1983; Morris et al., 1986; Frey and Morris,

\section{REFERENCES}

Aakalu, G., Smith, W. B., Nguyen, N., Jiang, C., and Schuman, E. M. (2001). Dynamic visualization of local protein synthesis in hippocampal neurons. Neuron 30, 489-502. doi: 10.1016/s0896-6273(01)00295-1

Abdou, K., Shehata, M., Choko, K., Nishizono, H., Matsuo, M., Muramatsu, S., et al. (2018). Synapse-specific representation of the identity of overlapping memory engrams. Science 360, 1227-1231. doi: 10.1126/science.aat3810

Abraham, W. C. (2008). Metaplasticity: tuning synapses and networks for plasticity. Nat. Rev. Neurosci. 9, 387-387. doi: 10.1038/nrn2356

Andersen, N., Krauth, N., and Nabavi, S. (2017). Hebbian plasticity in vivo: relevance and induction. Curr. Opin. Neurobiol. 45, 188-192. doi: 10.1016/j. conb.2017.06.001

Araki, Y., Zeng, M., Zhang, M., and Huganir, R. L. (2015). Rapid dispersion of SynGAP from synaptic spines triggers AMPA receptor insertion and spine enlargement during LTP. Neuron 85, 173-189. doi: 10.1016/j.neuron.2014. 12.023

Ashby, M. C., Sarah, A., Ralph, G. S., Uney, J., Collingridge, G. L., and Henley, J. M. (2004). Removal of AMPA receptors (AMPARs) from synapses is preceded by transient endocytosis of extrasynaptic AMPARs. J. Neurosci. 24, 5172-5176. doi: 10.1523/JNEUROSCI.1042-04.2004

Attardo, A., Fitzgerald, J. E., and Schnitzer, M. J. (2015). Impermanence of dendritic spines in live adult CA1 hippocampus. Nature 523:592. doi: 10.1038/nature14467

Bando, Y., Sakamoto, M., Kim, S., Ayzenshtat, I., and Yuste, R. (2019). Comparative evaluation of genetically encoded voltage indicators. Cell Rep. 26, 802.e4-813.e4. doi: 10.1016/j.celrep.2018.12.088
1997), the development of new techniques has enabled a shift in how the study of synaptic activity and potentiation is approached. Matsuzaki et al. (2004) pioneered the employment of imaging to describe synaptic plasticity. In recent years, more and more molecular techniques have been added to the toolbox to image and act on active synapses, with subcellular precision (Lin et al., 2013; Sinnen et al., 2017; Kakegawa et al., 2018). This is likely to expand further in the next future and find application in the study of learning and memory.

\section{AUTHOR CONTRIBUTIONS}

AC and FG conceived the project, discussed the ideas and wrote the manuscript. FG prepared the figures with input from AC. All authors contributed to the article and approved the submitted version.

\section{FUNDING}

This work was funded by the Italian Ministry for University and Research (Ministero dell'Istruzione, dell'Università e della Ricerca; grant PRIN 2017HPTFFC), Synaptic engrams in memory formation and recall.

\section{ACKNOWLEDGMENTS}

We thank Laura Marchetti (Universita' di Pisa), the SynActive group at Scuola Normale Superiore (Marco Mainardi, Ajesh Jacob, Andrea Faraone, Mariachiara Di Caprio), Richard GM Morris (University of Edinburgh), and Corinna Giorgi and Silvia Marinelli (EBRI) for fruitful discussions.

Barron, H. C., Vogels, T. P., Behrens, T. E., and Ramaswami, M. (2017). Inhibitory engrams in perception and memory. Proc. Natl. Acad. Sci. U S A 114, 6666-6674. doi: 10.1073/pnas.1701812114

Berlin, S., Szobota, S., Reiner, A., Carroll, E. C., Kienzler, M. A., Guyon, A., et al. (2016). A family of photoswitchable NMDA receptors. eLife 5:e12040. doi: 10.7554/eLife.12040

Biever, A., Donlin-Asp, P. G., and Schuman, E. M. (2019). Local translation in neuronal processes. Curr. Opin. Neurobiol. 57, 141-148. doi: 10.1016/j.conb. 2019.02.008

Bilz, F., Geurten, B. R., Hancock, C. E., Widmann, A., and Fiala, A. (2020). Visualization of a distributed synaptic memory code in the Drosophila brain. Neuron 106, 963.e4-976.e4. doi: 10.1016/j.neuron.2020. 03.010

Bliss, T. V., Collingridge, G. L., Morris, R. G., and Reymann, K. G. (2018). Longterm potentiation in the hippocampus: discovery, mechanisms and function. Neuroforum 24, A103-A120. doi: 10.1515/nf-2017-a059

Bliss, T. V., and Lømo, T. (1973). Long-lasting potentiation of synaptic transmission in the dentate area of the anaesthetized rabbit following stimulation of the perforant path. J. Physiol. 232, 331-356. doi: 10.1113/jphysiol.1973.sp010273

Bosch, M., Castro, J., Saneyoshi, T., Matsuno, H., Sur, M., and Hayashi, Y. (2014). Structural and molecular remodeling of dendritic spine substructures during long-term potentiation. Neuron 82, 444-459. doi: 10.1016/j.neuron.2014. 03.021

Bradshaw, K., Emptage, N., and Bliss, T. (2003). A role for dendritic protein synthesis in hippocampal late LTP. Eur. J. Neurosci. 18, 3150-3152. doi: 10.1111/j.1460-9568.2003.03054.x 
Bramham, C. R., Alme, M. N., Bittins, M., Kuipers, S. D., Nair, R. R., Pai, B., et al. (2010). The Arc of synaptic memory. Exp. Brain Res. 200, 125-140. doi: 10.1007/s00221-009-1959-2

Butko, M. T., Yang, J., Geng, Y., Kim, H. J., Jeon, N. L., Shu, X., et al. (2012). Fluorescent and photo-oxidizing TimeSTAMP tags track protein fates in light and electron microscopy. Nat. Neurosci. 15, 1742-1751. doi: 10.1038/nn.3246

Cai, D., Cohen, K. B., Luo, T., Lichtman, J. W., and Sanes, J. R. (2013). Improved tools for the Brainbow toolbox. Nat. Methods 10, 540-547. doi: 10.1038/ nmeth. 2450

Cajigas, I. J., Tushev, G., Will, T. J., Fuerst, N., and Schuman, E. M. (2012). The local transcriptome in the synaptic neuropil revealed by deep sequencing and high-resolution imaging. Neuron 74, 453-466. doi: 10.1016/j.neuron.2012. 02.036

Canepari, M., Willadt, S., Zecevic, D., and Vogt, K. E. (2010). Imaging inhibitory synaptic potentials using voltage sensitive dyes. Biophys. J. 98, 2032-2040. doi: 10.1016/j.bpj.2010.01.024

Castillo, P. E., Chiu, C. Q., and Carroll, R. C. (2011). Long-term plasticity at inhibitory synapses. Curr. Opin. Neurobiol. 21, 328-338. doi: 10.1016/j.conb. 2011.01.006

Chater, T. E., and Goda, Y. (2014). The role of AMPA receptors in postsynaptic mechanisms of synaptic plasticity. Front. Cell. Neurosci. 8:401. doi: 10.3389/fncel.2014.00401

Chen, X., Leischner, U., Rochefort, N. L., Nelken, I., and Konnerth, A. (2011). Functional mapping of single spines in cortical neurons in vivo. Nature 475, 501-505. doi: 10.1038/nature10193

Chen, B. E., Lendvai, B., Nimchinsky, E. A., Burbach, B., Fox, K., and Svoboda, K. (2000). Imaging high-resolution structure of GFP-expressing neurons in neocortex in vivo. Learn. Mem. 7, 433-441. doi: 10.1101/lm.32700

Chen, J. L., Villa, K. L., Cha, J. W., So, P. T. C., Kubota, Y., and Nedivi, E. (2012). Clustered dynamics of inhibitory synapses and dendritic spines in the adult neocortex. Neuron 74, 361-373. doi: 10.1016/j.neuron.2012.02.030

Chen, T.-W., Wardill, T. J., Sun, Y., Pulver, S. R., Renninger, S. L., Baohan, A., et al. (2013). Ultrasensitive fluorescent proteins for imaging neuronal activity. Nature 499, 295-300. doi: 10.1038/nature12354

Chevaleyre, V., and Piskorowski, R. (2014). Modulating excitation through plasticity at inhibitory synapses. Front. Cell. Neurosci. 8:93. doi: 10.3389/fncel. 2014.00093

Chiu, C. Q., Barberis, A., and Higley, M. J. (2019). Preserving the balance: diverse forms of long-term GABAergic synaptic plasticity. Nat. Rev. Neurosci. 20, 272-281. doi: 10.1038/s41583-019-0141-5

Choi, J.-H., Sim, S.-E., Kim, J.-I., Choi, D. I., Oh, J., Ye, S., et al. (2018). Interregional synaptic maps among engram cells underlie memory formation. Science 360, 430-435. doi: 10.1126/science.aas9204

Collingridge, G. L., Kehl, S. J., and McLennan, H. (1983). Excitatory amino acids in synaptic transmission in the Schaffer collateral-commissural pathway of the rat hippocampus. J. Physiol. 334, 33-46. doi: 10.1113/jphysiol.1983.sp014478

Collingridge, G. L., Peineau, S., Howland, J. G., and Wang, Y. T. (2010). Long-term depression in the CNS. Nat. Rev. Neurosci. 11, 459-473. doi: 10.1038/nrn2867

Dana, H., Mohar, B., Sun, Y., Narayan, S., Gordus, A., Hasseman, J. P., et al. (2016). Sensitive red protein calcium indicators for imaging neural activity. eLife 5:e12727. doi: 10.7554/eLife.12727

Dana, H., Sun, Y., Mohar, B., Hulse, B., Kerlin, A., Hasseman, J., et al. (2019). Highperformance calcium sensors for imaging activity in neuronal populations and microcompartments. Nat. Methods 16, 649-657. doi: 10.1038/s41592-0190435-6

Dawydow, A., Gueta, R., Ljaschenko, D., Ullrich, S., Hermann, M., Ehmann, N., et al. (2014). Channelrhodopsin-2-XXL, a powerful optogenetic tool for low-light applications. Proc. Natl. Acad. Sci. U S A 111, 13972-13977. doi: 10.1073/pnas.1408269111

de Solis, C. A., Morales, A. A., Hosek, M. P., Partin, A. C., and Ploski, J. E. (2017). Is Arc mRNA unique: a search for mRNAs that localize to the distal dendrites of dentate gyrus granule cells following neural activity. Front. Mol. Neurosci. 10:314. doi: 10.3389/fnmol.2017.00314

Diering, G. H., and Huganir, R. L. (2018). The AMPA receptor code of synaptic plasticity. Neuron 100, 314-329. doi: 10.1016/j.neuron.2018.10.018

Dore, K., Pao, Y., Lopez, J. S., Aronson, S., Zhan, H., Ghosh, S., et al. (2020). SYNPLA, a method to identify synapses displaying plasticity after learning. Proc. Natl. Acad. Sci. U S A 117, 3214-3219. doi: 10.1073/pnas.1919911117
Dreosti, E., Odermatt, B., Dorostkar, M. M., and Lagnado, L. (2009). A genetically encoded reporter of synaptic activity in vivo. Nat. Methods 6, 883-889. doi: 10.1038/nmeth.1399

Dudai, Y. (2011). “The engram revisited: on the elusive permanence of memory," in The Memory Process: Neuroscientific and Humanistic Perspectives, eds S. Nalbantian, P. M. Matthews and J. L. McClelland (Cambridge, MA: MIT Press), 29-40.

Dudai, Y., and Morris, R. G. M. (2013). Memorable trends. Neuron 80, 742-750. doi: 10.1016/j.neuron.2013.09.039

Dynes, J. L., and Steward, O. (2012). Arc mRNA docks precisely at the base of individual dendritic spines indicating the existence of a specialized microdomain for synapse-specific mRNA translation. J. Comp. Neurol. 520, 3105-3119. doi: 10.1002/cne.23073

Edelmann, E., Cepeda-Prado, E., and Leßmann, V. (2017). Coexistence of multiple types of synaptic plasticity in individual hippocampal CA1 pyramidal neurons. Front. Synaptic Neurosci. 9:7. doi: 10.3389/fnsyn.2017.00007

Eichenbaum, H. (2016). Still searching for the engram. Learn. Behav. 44, 209-222. doi: 10.3758/s13420-016-0218-1

El-Boustani, S., Ip, J. P., Breton-Provencher, V., Knott, G. W., Okuno, H., Bito, H., et al. (2018). Locally coordinated synaptic plasticity of visual cortex neurons in vivo. Science 360, 1349-1354. doi: 10.1126/science.aao0862

Fagiolini, M., Pizzorusso, T., Berardi, N., Domenici, L., and Maffei, L. (1994). Functional postnatal development of the rat primary visual cortex and the role of visual experience: dark rearing and monocular deprivation. Vision Res. 34, 709-720. doi: 10.1016/0042-6989(94)90210-0

Feese, B. D., Pafundo, D. E., Schmehl, M. N., and Kuhlman, S. J. (2018). Binocular deprivation induces both age-dependent and age-independent forms of plasticity in parvalbumin inhibitory neuron visual response properties. J. Neurophysiol. 119, 738-751. doi: 10.1152/jn.00386.2017

Fernández-Alfonso, T., Nadella, K. N. S., Iacaruso, M. F., Pichler, B., Roš, H., Kirkby, P. A., et al. (2014). Monitoring synaptic and neuronal activity in $3 \mathrm{D}$ with synthetic and genetic indicators using a compact acousto-optic lens two-photon microscope. J. Neurosci. Methods 222, 69-81. doi: 10.1016/j. jneumeth.2013.10.021

Fernandez-Moya, S. M., Bauer, K. E., and Kiebler, M. A. (2014). Meet the players: local translation at the synapse. Front. Mol. Neurosci. 7:84. doi: 10.3389/fnmol. 2014.00084

Flores, C. E., and Méndez, P. (2014). Shaping inhibition: activity dependent structural plasticity of GABAergic synapses. Front. Cell. Neurosci. 8:327. doi: 10.3389/fncel.2014.00327

Frank, A. C., Huang, S., Zhou, M., Gdalyahu, A., Kastellakis, G., Silva, T. K., et al. (2018). Hotspots of dendritic spine turnover facilitate clustered spine addition and learning and memory. Nat. Commun. 9:422. doi: 10.3410/f.732583490. 793543105

Frey, U., and Morris, R. G. (1997). Synaptic tagging and long-term potentiation. Nature 385, 533-536. doi: 10.1038/385533a0

Gallo, F. T., Katche, C., Morici, J. F., Medina, J. H., and Weisstaub, N. V. (2018). Immediate early genes, memory and psychiatric disorders: focus on c-Fos, Egr1 and Arc. Front. Behav. Neurosci. 12:79. doi: 10.3389/fnbeh.2018.00079

Gao, Y., Hisey, E., Bradshaw, T. W., Erata, E., Brown, W. E., Courtland, J. L., et al. (2019). Plug-and-play protein modification using homology-independent universal genome engineering. Neuron 103, 583.e8-597.e8. doi: 10.1016/j. neuron.2019.05.047

Garner, A. R., Rowland, D. C., Hwang, S. Y., Baumgaertel, K., Roth, B. L., Kentros, C., et al. (2012). Generation of a synthetic memory trace. Science 335, 1513-1516. doi: 10.1126/science. 1214985

Gauthier, J. L., and Tank, D. W. (2018). A dedicated population for reward coding in the hippocampus. Neuron 99, 179-193. doi: 10.1016/j.neuron.2018. 06.008

Ghandour, K., Ohkawa, N., Fung, C. C. A., Asai, H., Saitoh, Y., Takekawa, T., et al. (2019). Orchestrated ensemble activities constitute a hippocampal memory engram. Nat. Commun. 10:2637. doi: 10.1038/s41467-019-10683-2

Gökçe, O., Bonhoeffer, T., and Scheuss, V. (2016). Clusters of synaptic inputs on dendrites of layer 5 pyramidal cells in mouse visual cortex. eLife 5:e09222. doi: 10.7554/eLife.09222

Gobbo, F., Marchetti, L., Jacob, A., Pinto, B., Binini, N., Pecoraro Bisogni, F., et al. (2017). Activity-dependent expression of Channelrhodopsin at neuronal synapses. Nat. Commun. 8:1629. doi: 10.1038/s41467-017-01699-7 
Govindarajan, A., Kelleher, R. J., and Tonegawa, S. (2006). A clustered plasticity model of long-term memory engrams. Nat. Rev. Neurosci. 7, 575-583. doi: $10.1038 /$ nrn 1937

Gradinaru, V., Thompson, K. R., Zhang, F., Mogri, M., Kay, K., Schneider, M. B., et al. (2007). Targeting and readout strategies for fast optical neural control in vitro and in vivo. J. Neurosci. 27, 14231-14238. doi: 10.1523/JNEUROSCI. 3578-07.2007

Graves, A., Roth, R., Tan, H., Zhu, Q., Bygrave, A., Lopez-Ortega, E., et al. (2020). Visualizing synaptic plasticity in vivo by large-scale imaging of endogenous AMPA receptors. bioRxiv [Preprint]. doi: 10.1101/2020.03.01.972216

Grimley, J. S., Li, L., Wang, W., Wen, L., Beese, L. S., Hellinga, H. W., et al. (2013). Visualization of synaptic inhibition with an optogenetic sensor developed by cell-free protein engineering automation. J. Neurosci. 33, 16297-16309. doi: 10.1523/JNEUROSCI.4616-11.2013

Guenthner, C. J., Miyamichi, K., Yang, H. H., Heller, H. C., and Luo, L. (2013). Permanent genetic access to transiently active neurons via TRAP: targeted recombination in active populations. Neuron 78, 773-784. doi: 10.1016/j. neuron.2013.03.025

Gunaydin, L. A., Yizhar, O., Berndt, A., Sohal, V. S., Deisseroth, K., and Hegemann, P. (2010). Ultrafast optogenetic control. Nat. Neurosci. 13, 387-392. doi: 10.1038/nn.2495

Guzowski, J. F., Lyford, G. L., Stevenson, G. D., Houston, F. P., McGaugh, J. L., Worley, P. F., et al. (2000). Inhibition of activity-dependent arc protein expression in the rat hippocampus impairs the maintenance of long-term potentiation and the consolidation of long-term memory. J. Neurosci. 20, 3993-4001. doi: 10.1523/JNEUROSCI.20-11-03993.2000

Guzowski, J. F., McNaughton, B. L., Barnes, C. A., and Worley, P. F. (1999). Environment-specific expression of the immediate-early gene Arc in hippocampal neuronal ensembles. Nat. Neurosci. 2, 1120-1124. doi: $10.1038 / 16046$

Haery, L., Deverman, B. E., Matho, K. S., Cetin, A., Woodard, K., Cepko, C., et al. (2019). Adeno-associated virus technologies and methods for targeted neuronal manipulation. Front. Neuroanat. 13:93. doi: 10.3389/fnana.2019.00093

Han, J.-H., Kushner, S. A., Yiu, A. P., Hsiang, H.-L. L., Buch, T., Waisman, A., et al. (2009). Selective erasure of a fear memory. Science 323, 1492-1496. doi: 10.1126/science.1164139

Hanley, J. G. (2014). Actin-dependent mechanisms in AMPA receptor trafficking. Front. Cell. Neurosci. 8:381. doi: 10.3389/fncel.2014.00381

Hartman, K. N., Pal, S. K., Burrone, J., and Murthy, V. N. (2006). Activitydependent regulation of inhibitory synaptic transmission in hippocampal neurons. Nat. Neurosci. 9:642. doi: 10.1038/nn1677

Harvey, C. D., and Svoboda, K. (2007). Locally dynamic synaptic learning rules in pyramidal neuron dendrites. Nature 450, 1195-1200. doi: 10.1038/nature06416

Hayashi-Takagi, A., Yagishita, S., Nakamura, M., Shirai, F., Wu, Y. I., Loshbaugh, A. L., et al. (2015). Labelling and optical erasure of synaptic memory traces in the motor cortex. Nature 525, 333-338. doi: $10.1038 /$ nature15257

He, H.-Y., Shen, W., Hiramoto, M., and Cline, H. T. (2016). Experience-dependent bimodal plasticity of inhibitory neurons in early development. Neuron 90, 1203-1214. doi: 10.1016/j.neuron.2016.04.044

Herring, B. E., and Nicoll, R. A. (2016). Long-term potentiation: from CaMKII to AMPA receptor trafficking. Annu. Rev. Physiol. 78, 351-365. doi: 10.1146/annurev-physiol-021014-071753

Higley, M. J., and Sabatini, B. L. (2012). Calcium signaling in dendritic spines. Cold Spring Harb. Perspect. Biol. 4:a005686. doi: 10.1101/cshperspect.a005686

Holt, C. E., Martin, K. C., and Schuman, E. M. (2019). Local translation in neurons: visualization and function. Nat. Struct. Mol. Biol. 26, 557-566. doi: 10.1038/s41594-019-0263-5

Holtmaat, A., and Svoboda, K. (2009). Experience-dependent structural synaptic plasticity in the mammalian brain. Nat. Rev. Neurosci. 10, 647-658. doi: 10.1038/nrn2699

Hoshiba, Y., Wada, T., and Hayashi-Takagi, A. (2017). Synaptic ensemble underlying the selection and consolidation of neuronal circuits during learning. Front. Neural Circuits 11:12. doi: 10.3389/fncir.2017.00012

Ifrim, M. F., Williams, K. R., and Bassell, G. J. (2015). Single-molecule imaging of PSD-95 mRNA translation in dendrites and its dysregulation in a mouse model of Fragile X syndrome. J. Neurosci. 35, 7116-7130. doi: 10.1523/JNEUROSCI. 2802-14.2015
Inoue, M., Takeuchi, A., Manita, S., Horigane, S., Sakamoto, M., Kawakami, R., et al. (2019). Rational engineering of XCaMPs, a multicolor GECI suite for in vivo imaging of complex brain circuit dynamics. Cell 177, 1346.e24-1360.e24. doi: 10.1016/j.cell.2019.04.007

Jakkamsetti, V., Tsai, N.-P., Gross, C., Molinaro, G., Collins, K. A., Nicoletti, F., et al. (2013). Experience-induced Arc/Arg3. 1 primes CA1 pyramidal neurons for metabotropic glutamate receptor-dependent long-term synaptic depression. Neuron 80, 72-79. doi: 10.1016/j.neuron.2013.07.020

Jensen, T. P., Zheng, K., Cole, N., Marvin, J. S., Looger, L. L., and Rusakov, D. A. (2019). Multiplex imaging relates quantal glutamate release to presynaptic $\mathrm{Ca}^{2+}$ homeostasis at multiple synapses in situ. Nat. Commun. 10:1414. doi: 10.1038/s41467-019-09216-8

Josselyn, S. A., Köhler, S., and Frankland, P. W. (2015). Finding the engram. Nat. Rev. Neurosci. 16, 521-534. doi: 10.1038/nrn4000

Josselyn, S. A., Köhler, S., and Frankland, P. W. (2017). Heroes of the engram. J. Neurosci. 37, 4647-4657. doi: 10.1523/JNEUROSCI.0056-17.2017

Josselyn, S. A., and Tonegawa, S. (2020). Memory engrams: recalling the past and imagining the future. Science 367:eaaw4325. doi: 10.1126/science.aaw4325

Kakegawa, W., Katoh, A., Narumi, S., Miura, E., Motohashi, J., Takahashi, A., et al. (2018). Optogenetic control of synaptic AMPA receptor endocytosis reveals roles of LTD in motor learning. Neuron 99, 985-998. doi: 10.1016/j.neuron. 2018.07.034

Kang, H., and Schuman, E. (1996). A requirement for local protein synthesis in neurotrophin-induced hippocampal synaptic plasticity. Science 273, 1402-1406. doi: 10.1126/science.273.5280.1402

Kano, M. (1995). Plasticity of inhibitory synapses in the brain: a possible memory mechanism that has been overlooked. Neurosci. Res. 21, 177-182. doi: 10.1016/0168-0102(94)00860-i

Kastellakis, G., Cai, D. J., Mednick, S. C., Silva, A. J., and Poirazi, P. (2015). Synaptic clustering within dendrites: an emerging theory of memory formation. Prog. Neurobiol. 126, 19-35. doi: 10.1016/j.pneurobio.2014.12.002

Kavalali, E. T., and Jorgensen, E. M. (2014). Visualizing presynaptic function. Nat. Neurosci. 17, 10-16. doi: 10.1038/nn.3578

Kawashima, T., Kitamura, K., Suzuki, K., Nonaka, M., Kamijo, S., TakemotoKimura, S., et al. (2013). Functional labeling of neurons and their projections using the synthetic activity-dependent promoter E-SARE. Nat. Methods 10, 889-895. doi: 10.1038/nmeth.2559

Kawashima, T., Okuno, H., and Bito, H. (2014). A new era for functional labeling of neurons: activity-dependent promoters have come of age. Front. Neural Circuits 8:37. doi: 10.3389/fncir.2014.00037

Keck, T., Scheuss, V., Jacobsen, R. I., Wierenga, C. J., Eysel, U. T., Bonhoeffer, T., et al. (2011). Loss of sensory input causes rapid structural changes of inhibitory neurons in adult mouse visual cortex. Neuron 71, 869-882. doi: 10.1016/j. neuron.2011.06.034

Kelleher, R. J. III., Govindarajan, A., and Tonegawa, S. (2004). Translational regulatory mechanisms in persistent forms of synaptic plasticity. Neuron 44 59-73. doi: 10.1016/j.neuron.2004.09.013

Kemp, A., and Manahan-Vaughan, D. (2007). Hippocampal long-term depression: master or minion in declarative memory processes? Trends Neurosci. 30, 111-118. doi: 10.1016/j.tins.2007.01.002

Kim, J., Kwon, J.-T., Kim, H.-S., Josselyn, S. A., and Han, J.-H. (2014). Memory recall and modifications by activating neurons with elevated CREB. Nat. Neurosci. 17, 65-72. doi: 10.1038/nn.3592

Kim, J., Zhao, T., Petralia, R. S., Yu, Y., Peng, H., Myers, E., et al. (2011). mGRASP enables mapping mammalian synaptic connectivity with light microscopy. Nat. Methods 9, 96-102. doi: 10.1038/nmeth.1784

Kitamura, T., Ogawa, S. K., Roy, D. S., Okuyama, T., Morrissey, M. D., Smith, L. M., et al. (2017). Engrams and circuits crucial for systems consolidation of a memory. Science 356, 73-78. doi: 10.1126/science. aam6808

Kleindienst, T., Winnubst, J., Roth-Alpermann, C., Bonhoeffer, T., and Lohmann, C. (2011). Activity-dependent clustering of functional synaptic inputs on developing hippocampal dendrites. Neuron 72, 1012-1024. doi: 10.1016/j.neuron.2011.10.015

Kobayashi, H., Yamamoto, S., Maruo, T., and Murakami, F. (2005). Identification of a cis-acting element required for dendritic targeting of activity-regulated cytoskeleton-associated protein mRNA. Eur. J. Neurosci. 22, 2977-2984. doi: 10.1111/j.1460-9568.2005.04508.x 
Kopec, C. D., Li, B., Wei, W., Boehm, J., and Malinow, R. (2006). Glutamate receptor exocytosis and spine enlargement during chemically induced long-term potentiation. J. Neurosci. 26, 2000-2009. doi: 10.1523/JNEUROSCI. 3918-05.2006

Kornau, H.-C., Schenker, L. T., Kennedy, M. B., and Seeburg, P. H. (1995). Domain interaction between NMDA receptor subunits and the postsynaptic density protein PSD-95. Science 269, 1737-1740. doi: 10.1126/science.7569905

Kotlikoff, M. I. (2007). Genetically encoded $\mathrm{Ca}^{2+}$ indicators: using genetics and molecular design to understand complex physiology. J. Physiol. 578, 55-67. doi: 10.1113/jphysiol.2006.120212

Kubota, Y., Karube, F., Nomura, M., and Kawaguchi, Y. (2016). The diversity of cortical inhibitory synapses. Front. Neural Circuits 10:27. doi: 10.3389/fncir. 2016.00027

Langille, J. J., and Brown, R. E. (2018). The synaptic theory of memory: a historical survey and reconciliation of recent opposition. Front. Syst. Neurosci. 12:52. doi: 10.3389/fnsys.2018.00052

Lee, H., Oh, W. C., Seong, J., and Kim, J. (2016). Advanced fluorescence proteinbased synapse-detectors. Front. Synaptic Neurosci. 8:16. doi: 10.3389/fnsyn. 2016.00016

Leopold, A. V., Chernov, K. G., and Verkhusha, V. V. (2018). Optogenetically controlled protein kinases for regulation of cellular signaling. Chem. Soc. Rev. 47, 2454-2484. doi: 10.1039/c7cs00404d

Leopold, A. V., Shcherbakova, D. M., and Verkhusha, V. V. (2019). Fluorescent biosensors for neurotransmission and neuromodulation: engineering and applications. Front. Cell. Neurosci. 13:474. doi: 10.3389/fncel.2019.00474

Lin, Y., Bloodgood, B. L., Hauser, J. L., Lapan, A. D., Koon, A. C., Kim, T.-K., et al. (2008). Activity-dependent regulation of inhibitory synapse development by Npas4. Nature 455, 1198-1204. doi: 10.1038/nature07319

Lin, J. Y., Sann, S. B., Zhou, K., Nabavi, S., Proulx, C. D., Malinow, R., et al. (2013). Optogenetic inhibition of synaptic release with chromophore-assisted light inactivation (CALI). Neuron 79, 241-253. doi: 10.1016/j.neuron.2013. 05.022

Lin, M. Z., and Schnitzer, M. J. (2016). Genetically encoded indicators of neuronal activity. Nat. Neurosci. 19, 1142-1153. doi: 10.1038/nn.4359

Lisman, J., Cooper, K., Sehgal, M., and Silva, A. J. (2018). Memory formation depends on both synapse-specific modifications of synaptic strength and cell-specific increases in excitability. Nat. Neurosci. 21, 309-314. doi: 10.1038/ s41593-018-0076-6

Lisman, J., Yasuda, R., and Raghavachari, S. (2012). Mechanisms of CaMKII action in long-term potentiation. Nat. Rev. Neurosci. 13, 169-182. doi: 10.1038/ nrn3192

Liu, X., Ramirez, S., Pang, P. T., Puryear, C. B., Govindarajan, A., Deisseroth, K., et al. (2012). Optogenetic stimulation of a hippocampal engram activates fear memory recall. Nature 484, 381-385. doi: 10.1038/nature11028

Lledo, P.-M., Hjelmstad, G. O., Mukherji, S., Soderling, T. R., Malenka, R. C., and Nicoll, R. A. (1995). Calcium/calmodulin-dependent kinase II and long-term potentiation enhance synaptic transmission by the same mechanism. Proc. Natl. Acad. Sci. U S A 92, 11175-11179. doi: 10.1073/pnas.92.24. 11175

Lu, R., Sun, W., Liang, Y., Kerlin, A., Bierfeld, J., Seelig, J. D., et al. (2017). Videorate volumetric functional imaging of the brain at synaptic resolution. Nat. Neurosci. 20, 620-628. doi: 10.1364/brain.2017.brs2b.4

Lyford, G. L., Yamagata, K., Kaufmann, W. E., Barnes, C. A., Sanders, L. K., Copeland, N. G., et al. (1995). Arc, a growth factor and activity-regulated gene, encodes a novel cytoskeleton-associated protein that is enriched in neuronal dendrites. Neuron 14, 433-445. doi: 10.1016/0896-6273(95)90299-6

Macpherson, L. J., Zaharieva, E. E., Kearney, P. J., Alpert, M. H., Lin, T.-Y., Turan, Z., et al. (2015). Dynamic labelling of neural connections in multiple colours by trans-synaptic fluorescence complementation. Nat. Commun. 6:10024. doi: $10.1038 /$ ncomms 10024

Maffei, A. (2011). The many forms and functions of long term plasticity at GABAergic synapses. Neural Plast. 2011:254724. doi: 10.1155/2011/ 254724

Magnus, C. J., Lee, P. H., Atasoy, D., Su, H. H., Looger, L. L., and Sternson, S. M. (2011). Chemical and genetic engineering of selective ion channel-ligand interactions. Science 333, 1292-1296. doi: 10.1126/science.1206606

Mainardi, M., Gobbo, F., Jacob, A., Zentilin, L., Caterino, C., Cellerino, A., et al. (2018). "Purification and proteomic profiling of PSD-95 interactors at in vivo potentiated synapses.," in Program No. 444.04. 2018 Neuroscience Meeting Planner, 2018. Online (San Diego, CA: Society for Neuroscience).

Makino, H., and Malinow, R. (2011). Compartmentalized versus global synaptic plasticity on dendrites controlled by experience. Neuron 72, 1001-1011. doi: 10.1016/j.neuron.2011.09.036

Mao, T., O'Connor, D. H., Scheuss, V., Nakai, J., and Svoboda, K. (2008). Characterization and subcellular targeting of GCaMP-type genetically-encoded calcium indicators. PLoS One 3:e1796. doi: 10.1371/journal.pone.0001796

Marshel, J. H., Kim, Y. S., Machado, T. A., Quirin, S., Benson, B., Kadmon, J., et al. (2019). Cortical layer-specific critical dynamics triggering perception. Science 365:eaaw5202. doi: 10.1126/science.aaw5202

Martin, S. J., Grimwood, P. D., and Morris, R. G. (2000). Synaptic plasticity and memory: an evaluation of the hypothesis. Annu. Rev. Neurosci. 23, 649-711. doi: 10.1146/annurev.neuro.23.1.649

Martin, S. J., and Morris, R. G. M. (2002). New life in an old idea: the synaptic plasticity and memory hypothesis revisited. Hippocampus 12, 609-636. doi: 10.1002/hipo.10107

Marvin, J. S., Borghuis, B. G., Tian, L., Cichon, J., Harnett, M. T., Akerboom, J., et al. (2013). An optimized fluorescent probe for visualizing glutamate neurotransmission. Nat. Methods 10, 162-170. doi: 10.1038/nmeth.2333

Marvin, J. S., Scholl, B., Wilson, D. E., Podgorski, K., Kazemipour, A., Mueller, J. A., et al. (2018). Stability, affinity, and chromatic variants of the glutamate sensor iGluSnFR. Nat. Methods 15, 936-939. doi: 10.1038/s41592018-0171-3

Marvin, J. S., Shimoda, Y., Magloire, V., Leite, M., Kawashima, T., Jensen, T. P., et al. (2019). A genetically encoded fluorescent sensor for in vivo imaging of GABA. Nat. Methods 16, 763-770. doi: 10.1038/s41592-019-0471-2

Matsuo, N., Reijmers, L., and Mayford, M. (2008). Spine-type-specific recruitment of newly synthesized AMPA receptors with learning. Science 319, 1104-1107. doi: $10.1126 /$ science. 1149967

Matsuzaki, M., Honkura, N., Ellis-Davies, G. C., and Kasai, H. (2004). Structural basis of long-term potentiation in single dendritic spines. Nature 429, 761-766. doi: $10.1038 /$ nature 02617

Mattis, J., Tye, K. M., Ferenczi, E. A., Ramakrishnan, C., O’Shea, D. J., Prakash, R., et al. (2011). Principles for applying optogenetic tools derived from direct comparative analysis of microbial opsins. Nat. Methods 9, 159-172. doi: $10.1038 /$ nmeth. 1808

Mayford, M. (2014). The search for a hippocampal engram. Philos. Trans. R. Soc. Lond. B Biol. Sci. 369:20130161. doi: 10.1098/rstb.2013.0161

Mayford, M., Siegelbaum, S. A., and Kandel, E. R. (2012). Synapses and memory storage. Cold Spring Harb. Perspect. Biol. 4:a005751. doi: 10.1101/cshperspect. a005751

Meng, G., Liang, Y., Sarsfield, S., Jiang, W., Lu, R., Dudman, J. T., et al. (2019). High-throughput synapse-resolving two-photon fluorescence microendoscopy for deep-brain volumetric imaging in vivo. eLife 8:e40805. doi: 10.7554/eLife. 40805

Meyer, D., Bonhoeffer, T., and Scheuss, V. (2014). Balance and stability of synaptic structures during synaptic plasticity. Neuron 82, 430-443. doi: 10.1016/j. neuron.2014.02.031

Mikhaylova, M., and Kreutz, M. R. (2018). Clustered plasticity in Long-Term Potentiation: how strong synapses persist to maintain long-term memory. Neuroforum 24, A127-A132. doi: 10.1515/nf-2018-A006

Minatohara, K., Akiyoshi, M., and Okuno, H. (2016). Role of immediate-early genes in synaptic plasticity and neuronal ensembles underlying the memory trace. Front. Mol. Neurosci. 8:78. doi: 10.3389/fnmol.2015.00078

Moeyaert, B., Holt, G., Madangopal, R., Perez-Alvarez, A., Fearey, B. C., Trojanowski, N. F., et al. (2018). Improved methods for marking active neuron populations. Nat. Commun. 9:4440. doi: 10.1038/s41467-018-06935-2

Mongillo, G., Rumpel, S., and Loewenstein, Y. (2017). Intrinsic volatility of synaptic connections-a challenge to the synaptic trace theory of memory. Curr. Opin. Neurobiol. 46, 7-13. doi: 10.1016/j.conb.2017.06.006

Morris, R. (2006). Elements of a neurobiological theory of hippocampal function: the role of synaptic plasticity, synaptic tagging and schemas. Eur. J. Neurosci. 23, 2829-2846. doi: 10.1111/j.1460-9568.2006.04888.x

Morris, R. G. (2003). Long-term potentiation and memory. Philos. Trans. R. Soc. Lond. B Biol. Sci. 358, 643-647. doi: 10.1098/rstb.2002.1230

Morris, R., Anderson, E., Lynch, G. A., and Baudry, M. (1986). Selective impairment of learning and blockade of long-term potentiation by an 
N-methyl-D-aspartate receptor antagonist, AP5. Nature 319, 774-776. doi: 10.1038/319774a0

Müllner, F. E., Wierenga, C. J., and Bonhoeffer, T. (2015). Precision of inhibition: dendritic inhibition by individual gabaergic synapses on hippocampal pyramidal cells is confined in space and time. Neuron 87, 576-589. doi: 10.1016/j.neuron.2015.07.003

Murakoshi, H., Shin, M. E., Parra-Bueno, P., Szatmari, E. M., Shibata, A. C., and Yasuda, R. (2017). Kinetics of endogenous CaMKII required for synaptic plasticity revealed by optogenetic kinase inhibitor. Neuron 94:690. doi: 10.1016/j.neuron.2017.04.027

Na, Y., Park, S., Lee, C., Kim, D.-K., Park, J. M., Sockanathan, S., et al. (2016). Realtime imaging reveals properties of glutamate-induced Arc/Arg 3.1 translation in neuronal dendrites. Neuron 91, 561-573. doi: 10.1016/j.neuron.2016.06.017

Nabavi, S., Fox, R., Proulx, C., Lin, J., Tsien, R., and Malinow, R. (2014). Engineering a memory with LTD and LTP. Nature 511, 348-352. doi: $10.1038 /$ nature 13294

Nakai, J., Ohkura, M., and Imoto, K. (2001). A high signal-to-noise $\mathrm{Ca}^{2+}$ probe composed of a single green fluorescent protein. Nat. Biotechnol. 19, 137-141. doi: $10.1038 / 84397$

Nomoto, M., and Inokuchi, K. (2018). Behavioral, cellular and synaptic tagging frameworks. Neurobiol. Learn. Mem. 153, 13-20. doi: 10.1016/j.nlm.2018. 03.010

O’Banion, C. P., Priestman, M. A., Hughes, R. M., Herring, L. E., Capuzzi, S. J., and Lawrence, D. S. (2018). Design and profiling of a subcellular targeted optogenetic cAMP-dependent protein kinase. Cell Chem. Biol. 25, 100.e8-109.e8. doi: 10.1016/j.chembiol.2017.09.011

Ohkawa, N., Saitoh, Y., Suzuki, A., Tsujimura, S., Murayama, E., Kosugi, S., et al. (2015). Artificial association of pre-stored information to generate a qualitatively new memory. Cell Rep. 11, 261-269. doi: 10.1016/j.celrep.2015. 03.017

Okuno, H., Akashi, K., Ishii, Y., Yagishita-Kyo, N., Suzuki, K., Nonaka, M., et al. (2012). Inverse synaptic tagging of inactive synapses via dynamic interaction of Arc/Arg3. 1 with CaMKII $\beta$. Cell 149, 886-898. doi: 10.1016/j.cell.2012. 02.062

Padamesey, Z., and Emptage, N. J. (2011). Imaging synaptic plasticity. Mol. Brain 4:36. doi: 10.1186/1756-6606-4-36

Pech, U., Revelo, N. H., Seitz, K. J., Rizzoli, S. O., and Fiala, A. (2015). Optical dissection of experience-dependent pre-and postsynaptic plasticity in the Drosophila brain. Cell Rep. 10, 2083-2095. doi: 10.1016/j.celrep.2015.02.065

Pelkey, K. A., Chittajallu, R., Craig, M. T., Tricoire, L., Wester, J. C., and McBain, C. J. (2017). Hippocampal GABAergic inhibitory interneurons. Physiol. Rev. 97, 1619-1747. doi: 10.1152/physrev.00007.2017

Pereira, D. B., Schmitz, Y., Mészáros, J., Merchant, P., Hu, G., Li, S., et al. (2016). Fluorescent false neurotransmitter reveals functionally silent dopamine vesicle clusters in the striatum. Nat. Neurosci. 19, 578-586. doi: 10.1038/ nn. 4252

Perez-Alvarez, A., Schulze, C., Fearey, B. C., Moeyaert, B., O’Toole, R. J., Mohr, M. A., et al. (2020). Freeze-frame imaging of synaptic activity using SynTagMA. Nat. Commun. 11:2464. doi: 10.1038/s41467-020 $-16315-4$

Pfeiffer, T., Poll, S., Bancelin, S., Angibaud, J., Inavalli, V. K., Keppler, K., et al. (2018). Chronic 2P-STED imaging reveals high turnover of dendritic spines in the hippocampus in vivo. eLife 7:e34700. doi: 10.7554/elife.34700

Pinkstaff, J. K., Chappell, S. A., Mauro, V. P., Edelman, G. M., and Krushel, L. A. (2001). Internal initiation of translation of five dendritically localized neuronal mRNAs. Proc. Natl. Acad. Sci. U S A 98, 2770-2775. doi: 10.1073/pnas. 051623398

Plath, N., Ohana, O., Dammermann, B., Errington, M. L., Schmitz, D., Gross, C., et al. (2006). Arc/Arg3. 1 is essential for the consolidation of synaptic plasticity and memories. Neuron 52, 437-444. doi: 10.1016/j.neuron.2006.08.024

Poo, M., Pignatelli, M., Ryan, T. J., Tonegawa, S., Bonhoeffer, T., Martin, K. C., et al. (2016). What is memory? The present state of the engram. BMC Biol. 14:40. doi: 10.1186/s12915-016-0261-6

Pouget, A., Beck, J. M., Ma, W. J., and Latham, P. E. (2013). Probabilistic brains: knowns and unknowns. Nat. Neurosci. 16, 1170-1178. doi: 10.1038/nn.3495

Ramirez, S., Liu, X., Lin, P.-A., Suh, J., Pignatelli, M., Redondo, R. L., et al. (2013). Creating a false memory in the hippocampus. Science 341, 387-391. doi: $10.1126 /$ science. 1239073
Reijmers, L. G., Perkins, B. L., Matsuo, N., and Mayford, M. (2007). Localization of a stable neural correlate of associative memory. Science 317, 1230-1233. doi: 10.1126/science.1143839

Reutsky-Gefen, I., Golan, L., Farah, N., Schejter, A., Tsur, L., Brosh, I., et al. (2013). Holographic optogenetic stimulation of patterned neuronal activity for vision restoration. Nat. Commun. 4:1509. doi: 10.1038/ncomms 2500

Reymann, K. G., and Frey, J. U. (2007). The late maintenance of hippocampal LTP: requirements, phases, "synaptic tagging", "late-associativity" and implications. Neuropharmacology 52, 24-40. doi: 10.1016/j.neuropharm.2006. 07.026

Rogerson, T., Cai, D. J., Frank, A., Sano, Y., Shobe, J., Lopez-Aranda, M. F., et al. (2014). Synaptic tagging during memory allocation. Nat. Rev. Neurosci. 15, 157-169. doi: 10.1038/nrn3667

Ron, S., Dudai, Y., and Segal, M. (2011). Overexpression of PKM $\zeta$ alters morphology and function of dendritic spines in cultured cortical neurons. Cereb. Cortex 22, 2519-2528. doi: 10.1093/cercor/bhr323

Rossato, J. I., Moreno, A., Genzel, L., Yamasaki, M., Takeuchi, T., Canals, S., et al. (2018). Silent learning. Curr. Biol. 28, 3508.e5-3515.e5. doi: 10.1016/j.cub.2018. 09.012

Routtenberg, A. (2015). Is the place cell a "supple" engram? Hippocampus 25, 753-755. doi: 10.1002/hipo.22446

Ryan, T. J., Roy, D. S., Pignatelli, M., Arons, A., and Tonegawa, S. (2015). Engram cells retain memory under retrograde amnesia. Science 348, 1007-1013. doi: $10.1126 /$ science.aaa5542

Sakaguchi, M., and Hayashi, Y. (2012). Catching the engram: strategies to examine the memory trace. Mol. Brain 5:32. doi: 10.1186/1756-6606-5-32

Sato, S. S., Artoni, P., Landi, S., Cozzolino, O., Parra, R., Pracucci, E., et al. (2017) Simultaneous two-photon imaging of intracellular chloride concentration and $\mathrm{pH}$ in mouse pyramidal neurons in vivo. Proc. Natl. Acad. Sci. U S A 114, E8770-E8779. doi: 10.1073/pnas.1702861114

Schacter, D. L., Eich, J. E., and Tulving, E. (1978). Richard Semon's theory of memory. J. Verb. Learn. Verb. Behav. 17, 721-743.

Scheuss, V., and Bonhoeffer, T. (2014). Function of dendritic spines on hippocampal inhibitory neurons. Cereb. Cortex 24, 3142-3153. doi: 10.1093/cercor/bht171

Schuette, S. R., Fernández-Fernández, D., Lamla, T., Rosenbrock, H., and Hobson, S. (2016). Overexpression of protein kinase $M \zeta$ in the hippocampus enhances long-term potentiation and long-term contextual but not cued fear memory in rats. J. Neurosci. 36, 4313-4324. doi: 10.1523/jneurosci.3600-15. 2016

Schultz, S. R., Copeland, C. S., Foust, A. J., Quicke, P., and Schuck, R. (2016). Advances in two-photon scanning and scanless microscopy technologies for functional neural circuit imaging. Proc. IEEE Inst. Electr. Electron. Eng. 105, 139-157. doi: 10.1109/jproc.2016.2577380

Shehata, M., Abdou, K., Choko, K., Matsuo, M., Nishizono, H., and Inokuchi, K. (2018). Autophagy enhances memory erasure through synaptic destabilization. J. Neurosci. 38, 3809-3822. doi: 10.1523/jneurosci.350517.2018

Shen, Y., Rosendale, M., Campbell, R. E., and Perrais, D. (2014). pHuji, a $\mathrm{pH}$-sensitive red fluorescent protein for imaging of exo-and endocytosis. J. Cell Biol. 207, 419-432. doi: 10.1083/jcb.201404107

Sinnen, B. L., Bowen, A. B., Forte, J. S., Hiester, B. G., Crosby, K. C., Gibson, E. S., et al. (2017). Optogenetic control of synaptic composition and function. Neuron 93, 646.e5-660.e5. doi: 10.1016/j.neuron.2016.12.037

Sjulson, L., Cassataro, D., DasGupta, S., and Miesenböck, G. (2016). Cell-specific targeting of genetically encoded tools for neuroscience. Ann. Rev. Genet. 50, 571-594. doi: 10.1146/annurev-genet-120215-035011

Sossin, W. S. (2018). Memory synapses are defined by distinct molecular complexes: a proposal. Front. Synaptic Neurosci. 10:5. doi: 10.3389/fnsyn.2018. 00005

Squire, L. R. (1986). Mechanisms of memory. Science 232, 1612-1619. doi: $10.1126 /$ science. 3086978

Squire, L. R., Genzel, L., Wixted, J. T., and Morris, R. G. (2015). Memory consolidation. Cold Spring Harb. Perspect. Biol. 7:a021766. doi: $10.1101 /$ cshperspect.a021766

Steward, O., and Worley, P. F. (2001). Selective targeting of newly synthesized Arc mRNA to active synapses requires NMDA receptor activation. Neuron 30, 227-240. doi: 10.1016/s0896-6273(01)00275-6 
Südhof, T. C. (2012). Calcium control of neurotransmitter release. Cold Spring Harb. Perspect. Biol. 4:a011353. doi: 10.1101/cshperspect. a011353

Sutton, M. A., and Schuman, E. M. (2006). Dendritic protein synthesis, synaptic plasticity, and memory. Cell 127, 49-58. doi: 10.1016/j.cell.2006.09.014

Takahashi, N., Kitamura, K., Matsuo, N., Mayford, M., Kano, M., Matsuki, N., et al. (2012). Locally synchronized synaptic inputs. Science 335, 353-356. doi: $10.1126 /$ science. 1210362

Takeuchi, T., Duszkiewicz, A. J., and Morris, R. G. (2014). The synaptic plasticity and memory hypothesis: encoding, storage and persistence. Philos. Trans. R. Soc. Lond. B Biol. Sci. 369:20130288. doi: 10.1098/rstb.2013.0288

Takeuchi, T., Duszkiewicz, A. J., Sonneborn, A., Spooner, P. A., Yamasaki, M., Watanabe, M., et al. (2016). Locus coeruleus and dopaminergic consolidation of everyday memory. Nature 537, 357-362. doi: 10.1038/nature19325

Tanaka, H., and Hirano, T. (2012). Visualization of subunit-specific delivery of glutamate receptors to postsynaptic membrane during hippocampal long-term potentiation. Cell Rep. 1, 291-298. doi: 10.1016/j.celrep.2012. 02.004

Tian, L., Hires, S. A., Mao, T., Huber, D., Chiappe, M. E., Chalasani, S. H., et al. (2009). Imaging neural activity in worms, flies and mice with improved GCaMP calcium indicators. Nat. Methods 6, 875-881. doi: 10.1038/ nmeth.1398

Tonegawa, S., Liu, X., Ramirez, S., and Redondo, R. (2015a). Memory engram cells have come of age. Neuron 87, 918-931. doi: 10.1016/j.neuron.2015.08.002

Tonegawa, S., Pignatelli, M., Roy, D. S., and Ryan, T. J. (2015b). Memory engram storage and retrieval. Curr. Opin. Neurobiol. 35, 101-109. doi: 10.1016/j.conb. 2015.07.009

Tremblay, R., Lee, S., and Rudy, B. (2016). GABAergic interneurons in the neocortex: from cellular properties to circuits. Neuron 91, 260-292. doi: 10.1016/j.neuron.2016.06.033

Triller, A., Cluzeaud, F., Pfeiffer, F., Betz, H., and Korn, H. (1985). Distribution of glycine receptors at central synapses: an immunoelectron microscopy study. J. Cell Biol. 101, 683-688. doi: 10.1083/jcb.101.2.683

Turrigiano, G. G. (2017). The dialectic of Hebb and homeostasis. Philos. Trans. R. Soc. Lond. B Biol. Sci. 372:20160258. doi: 10.1098/rstb.2016.0258

Varga, Z., Jia, H., Sakmann, B., and Konnerth, A. (2011). Dendritic coding of multiple sensory inputs in single cortical neurons in vivo. Proc. Natl. Acad. Sci. U S A 108, 15420-15425. doi: 10.1073/pnas.1112355108

Verstraelen, P., Van Dyck, M., Verschuuren, M., Kashikar, N. D., Nuydens, R., Timmermans, J.-P., et al. (2018). Image-based profiling of synaptic connectivity in primary neuronal cell culture. Front. Neurosci. 12:389. doi: 10.3389/fnins. 2018.00389

Villa, K. L., Berry, K. P., Subramanian, J., Cha, J. W., Oh, W. C., Kwon, H.-B., et al. (2016). Inhibitory synapses are repeatedly assembled and removed at persistent sites in vivo. Neuron 89, 756-769. doi: 10.1016/j.neuron.2016.01.010

Viswanathan, S., Williams, M. E., Bloss, E. B., Stasevich, T. J., Speer, C. M., Nern, A., et al. (2015). High-performance probes for light and electron microscopy. Nat. Methods 12, 568-576. doi: 10.1038/nmeth.3365

Wang, Y., Liu, Y., Wang, L., Tang, W., and Wang, Z. (2019). Silent synapse unsilencing in hippocampal CA1 neurons for associative fear memory storage. Cereb. Cortex 29, 4067-4076. doi: 10.1093/cercor/bhy288

Wang, S.-H., Redondo, R. L., and Morris, R. G. M. (2010). Relevance of synaptic tagging and capture to the persistence of long-term potentiation and everyday spatial memory. Proc. Natl. Acad. Sci. U S A 107, 19537-19542. doi: $10.1073 /$ pnas. 1008638107

Wang, W., Wildes, C. P., Pattarabanjird, T., Sanchez, M. I., Glober, G. F., Matthews, G. A., et al. (2017). A light-and calcium-gated transcription factor for imaging and manipulating activated neurons. Nat. Biotechnol. 35, 864-871. doi: $10.1038 /$ nbt.3909

Whitlock, J. R., Heynen, A. J., Shuler, M. G., and Bear, M. F. (2006). Learning induces long-term potentiation in the hippocampus. Science 313, 1093-1097. doi: $10.1126 /$ science. 1128134
Wiegert, J. S., Mahn, M., Prigge, M., Printz, Y., and Yizhar, O. (2017). Silencing neurons: tools, applications and experimental constraints. Neuron 95, 504-529. doi: 10.1016/j.neuron.2017.06.050

Wiegert, J. S., Pulin, M., Gee, C. E., and Oertner, T. G. (2018). The fate of hippocampal synapses depends on the sequence of plasticity-inducing events. eLife 7:e39151. doi: 10.7554/elife.39151

Wierenga, C. J., Becker, N., and Bonhoeffer, T. (2008). GABAergic synapses are formed without the involvement of dendritic protrusions. Nat. Neurosci. 11, 1044-1052. doi: 10.1038/nn.2180

Williams, J. M., and Kyrke-Smith, M. (2018). Bridging synaptic and epigenetic maintenance mechanisms of the engram. Front. Mol. Neurosci. 11:369. doi: 10.3389/fnmol.2018.00369

Winnubst, J., Cheyne, J. E., Niculescu, D., and Lohmann, C. (2015). Spontaneous activity drives local synaptic plasticity in vivo. Neuron 87, 399-410. doi: 10.1016/j.neuron.2015.06.029

Winnubst, J., and Lohmann, C. (2012). Synaptic clustering during development and learning: the why, when and how. Front. Mol. Neurosci. 5:70. doi: 10.3389/fnmol.2012.00070

Wu, Y. I., Frey, D., Lungu, O. I., Jaehrig, A., Schlichting, I., Kuhlman, B., et al. (2009). A genetically encoded photoactivatable Rac controls the motility of living cells. Nature 461, 104-108. doi: 10.1038/nature08241

Wu, J., Liang, Y., Chen, S., Hsu, C.-L., Chavarha, M., Evans, S. W., et al. (2020). Kilohertz two-photon fluorescence microscopy imaging of neural activity in vivo. Nat. Methods 17, 287-290. doi: 10.1038/s41592-020$0762-7$

Xu, N., Harnett, M. T., Williams, S. R., Huber, D., O'Connor, D. H., Svoboda, K., et al. (2012). Nonlinear dendritic integration of sensory and motor input during an active sensing task. Nature 492, 247-251. doi: 10.1038/nature11601

Xu, T., Yu, X., Perlik, A. J., Tobin, W. F., Zweig, J. A., Tennant, K., et al. (2009). Rapid formation and selective stabilization of synapses for enduring motor memories. Nature 462, 915-919. doi: 10.1038/nature08389

Yang, G., Pan, F., and Gan, W.-B. (2009). Stably maintained dendritic spines are associated with lifelong memories. Nature 462, 920-924. doi: 10.1038 /nature08577

Yang, H. H., St-Pierre, F., Sun, X., Ding, X., Lin, M. Z., and Clandinin, T. R. (2016). Subcellular imaging of voltage and calcium signals reveals neural processing in vivo. Cell 166, 245-257. doi: 10.1016/j.cell.2016.05.031

Yap, E.-L., and Greenberg, M. E. (2018). Activity-regulated transcription: bridging the gap between neural activity and behavior. Neuron 100, 330-348. doi: 10.1016/j.neuron.2018.10.013

Yilmaz-Rastoder, E., Miyamae, T., Braun, A. E., and Thiels, E. (2011). LTPand LTD-inducing stimulations cause opposite changes in arc/arg3.1 mRNA level in hippocampal area CA1 in vivo. Hippocampus 21, 1290-1301. doi: 10.1002/hipo.20838

Zhang, Y., Cudmore, R. H., Lin, D.-T., Linden, D. J., and Huganir, R. L. (2015). Visualization of NMDA receptor-dependent AMPA receptor synaptic plasticity in vivo. Nat. Neurosci. 18, 402-407. doi: 10.1038/nn. 3936

Zong, W., Wu, R., Li, M., Hu, Y., Li, Y., Li, J., et al. (2017). Fast high-resolution miniature two-photon microscopy for brain imaging in freely behaving mice. Nat. Methods 14, 713-719. doi: 10.1038/nmeth.4305

Conflict of Interest: The authors declare that the research was conducted in the absence of any commercial or financial relationships that could be construed as a potential conflict of interest.

Copyright $\odot 2020$ Gobbo and Cattaneo. This is an open-access article distributed under the terms of the Creative Commons Attribution License (CC BY). The use, distribution or reproduction in other forums is permitted, provided the original author(s) and the copyright owner(s) are credited and that the original publication in this journal is cited, in accordance with accepted academic practice. No use, distribution or reproduction is permitted which does not comply with these terms. 